\title{
Analysis of Lead Assessor Feedback for CBA IPI \\ Assessments Conducted July 1998 - October 1999
}

Donna K. Dunaway, Ph.D.

Mui Leng Seow

Michele Baker

April 2000 



\section{Analysis of Lead Assessor Feedback for CBA IPI Assessments Conducted July 1998 - October 1999}

CMU/SEI-2000-TR-005

ESC-TR-2000-005

Donna K. Dunaway, Ph.D.

Mui Leng Seow

Michele Baker

April 2000

Software Engineering Process Management Program 
This report was prepared for the

SEI Joint Program Office

HQ ESC/DIB

5 Eglin Street

Hanscom AFB, MA 01731-2116

The ideas and findings in this report should not be construed as an official DoD position. It is published in the interest of scientific and technical information exchange.

FOR THE COMMANDER

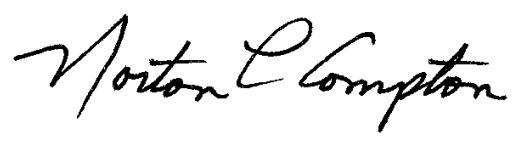

Norton L. Compton, Lt Col., USAF

SEI Joint Program Office

This work is sponsored by the U.S. Department of Defense. The Software Engineering Institute is a federally funded research and development center sponsored by the U.S. Department of Defense.

Copyright 2000 by Carnegie Mellon University.

NO WARRANTY

THIS CARNEGIE MELLON UNIVERSITY AND SOFTWARE ENGINEERING INSTITUTE MATERIAL IS FURNISHED ON AN "AS-IS" BASIS. CARNEGIE MELLON UNIVERSITY MAKES NO WARRANTIES OF ANY KIND, EITHER EXPRESSED OR IMPLIED, AS TO ANY MATTER INCLUDING, BUT NOT LIMITED TO, WARRANTY OF FITNESS FOR PURPOSE OR MERCHANTABILITY, EXCLUSIVITY, OR RESULTS OBTAINED FROM USE OF THE MATERIAL. CARNEGIE MELLON UNIVERSITY DOES NOT MAKE ANY WARRANTY OF ANY KIND WITH RESPECT TO FREEDOM FROM PATENT, TRADEMARK, OR COPYRIGHT INFRINGEMENT.

Use of any trademarks in this report is not intended in any way to infringe on the rights of the trademark holder.

Internal use. Permission to reproduce this document and to prepare derivative works from this document for internal use is granted, provided the copyright and "No Warranty" statements are included with all reproductions and derivative works.

External use. Requests for permission to reproduce this document or prepare derivative works of this document for external and commercial use should be addressed to the SEI Licensing Agent.

This work was created in the performance of Federal Government Contract Number F19628-95-C-0003 with Carnegie Mellon University for the operation of the Software Engineering Institute, a federally funded research and development center. The Government of the United States has a royalty-free government-purpose license to use, duplicate, or disclose the work, in whole or in part and in any manner, and to have or permit others to do so, for government purposes pursuant to the copyright license under the clause at 52.227-7013.

For information about purchasing paper copies of SEI reports, please visit the publications portion of our Web site (http://www.sei.cmu.edu/publications/pubweb.html). 


\section{Table of Contents}

Acknowledgements

Abstract vii

1 Purpose of Document 9

1.1 Data Analysis Process 9

1.1.1 Data Entry 9

1.1.2 Data Analysis 9

1.1.3 Data Reporting 10

1.2 Document Overview 10

2 Planning the Assessment 11

2.1 Assessment Materials 11

2.2 Team Composition 12

2.2.1 Team Size 12

2.2.2 Proportion of Members from Assessed Organizations $\quad 13$

2.2.3 Team Member Selection Guidelines 13

2.3 Assessed Organization 14

2.3.1 Business Goals 14

2.3.2 Organization Size 16

2.3.3 CMM Scope 17

2.4 Training 19

2.4.1 CMM Training 19

2.4.2 CBA IPI Team Training 20

2.4.2.1 Time Spent in CBA IPI Team Training 21

2.4.2.2 Team Members Waived from Team Training 22

2.4.2.3 Supplementary Materials 23

3 Conducting the Assessment 25

3.1 Maturity Questionnaires 25

3.2 Interviews 26

3.3 Documents Reviewed 26 
3.4 Level of Data Collection 28

3.5 Data Corroboration 29

3.6 Observations 29

3.7 Draft Findings 31

3.8 Type of Ratings 32

3.9 Decision Making Strategy 33

$4 \quad$ Reporting Results $\quad 35$

4.1 Sponsor Participation 35

4.2 Reports Submitted 36

5 Additional Questions $\quad 37$

5.1 Length of Assessments 37

5.2 Team Hours 37

5.2.1 Pre-onsite and On-Site Time Distribution 38

5.2.2 Team Hours Spent on Consolidation Activities $\quad 39$

5.2.3 Team Hours Required to Perform CBA IPI Activities $\quad 40$

6 Conclusion $\quad 43$

6.1 CBA IPI Requirements 43

6.2 Key Findings 43

6.3 Lead Assessor Requirements Checklist 44 


\section{List of Figures}

Figure 1: How Assessment Materials Were Obtained 11

Figure 2: Total Number Of Team Members 12

Figure 3: Proportion of Members from Assessed Organizations

Figure 4: Rating of Team Members Based on Selection Guidelines $\quad 14$

Figure 5: Business Goals 16

Figure 6: Number of People in the Organization 17

Figure 7: CMM Scope 18

Figure 8: Level 3 KPAs Selected in CMM Scope 19

Figure 9: CMM Training Used 20

Figure 10: Delivery Time for CBA IPI Team Training 21

Figure 11: Number of Team Members Waived From CBA IPI Team Training 22

Figure 12: Supplementary Materials Provided for CBA IPI Team Training 23

Figure 13: Types of Supplementary Materials 24

Figure 14: Number of Questionnaires Administered 25

Figure 15: Total Number of Interviewees 26

Figure 16: Number of Documents Reviewed 27

Figure 17: Level of Documentation Examined 28

Figure 18: Level of Data Collection 28

Figure 19: Number of Observations 30

Figure 20: Sufficiency of Coverage 30

Figure 21: Number of Draft Findings Presented 31

Figure 22: Number of Draft Finding Presentations 32

Figure 23: Level of Ratings Done 33

Figure 24: Sponsor Participation 35

Figure 25: Reports Submitted to the SEI 36

Figure 26: Number of Assessment Days 37

Figure 27: Average Distribution of Total Team Hours 39

Figure 28: Team Hours Spent on Consolidation Activities 39

Figure 29: Proportion of On-Site Team Hours Spent on Consolidation Activities 40

Figure 30: Time to Perform CBA IPI Activities 41 


\section{Acknowledgements}

Most of the analysis within this report was done by Mui Leng Seow. She did the work as part of an independent study for the Master of Software Engineering (MSE) program at Carnegie Mellon University. Dr. Dunaway was her independent study advisor, and together they defined this project. Our thanks to her for her valuable participation in this project.

Many thanks to Michele Baker who is a very valuable contributor to the SEI Appraiser Program. As the administrative coordinator, she tirelessly works with persons who want to become Lead Assessors in the SEI Appraiser Program. She supervises the handling of feedback from CBA IPI forms as well as administration of the assessment kits. The SEI Appraiser Program runs smoothly because of Michele's administrative skills and dedication.

Thanks to Claire Dixon who has been the technical editor of this report. Her contributions have made this report more clear, accurate, and readable. 


\section{Abstract}

In the Appraiser Program of the Software Engineering Institute (SEI), authorized Lead Assessors lead Capability Maturity Model-Based Appraisals for Internal Process Improvement (CBA IPI). At the conclusion of each assessment, they are required to submit certain artifacts to the SEI. Data from assessments is recorded to provide the community with information on the state of the software community's process maturity, as related to the Capability Maturity Model (CMM) for Software Version 1.1. These data can be viewed on the SEI Web site: $<$ URL http:// www.sei.cmu.edu/sema/profile.html $>$.

Additional feedback data are required of a Lead Assessor in order to monitor the consistency of use of the assessment method for quality control purposes. Data are collected from Lead Assessors, assessment team members, and sponsors of the assessments. The results reported in this document reflect information sent to the SEI by Lead Assessors through a Lead Assessor's Requirements Checklist. The checklist aids the Lead Assessors in keeping track of their implementation of each of the method's requirements. The checklist also provides information back to the community regarding metrics being reported by Lead Assessors; this helps in more effective planning for future assessments. In addition, the checklist acts as a quality control mechanism to monitor the consistency of use of each of the method's activities.

Thanks to the Lead Assessors who contributed the data in order that it can be shared with other Lead Assessors and the community. 


\section{Purpose of Document}

The main purpose of this document is to consolidate and analyze information from Lead Assessor Requirements Checklists that have been submitted by Lead Assessors in assessments conducted using the Capability Maturity Model -Based Appraisal for Internal Process Improvement (CBA IPI) method.

The audience for this document is the community of software developers who are contemplating having a CBA IPI assessment in their organization and Lead Assessors who are interested in learning more about others' experiences in order to improve their own planning and use of the CBA IPI method.

\subsection{Data Analysis Process}

A total of 83 Lead Assessor Requirements Checklists were completed and submitted as of November 1, 1999, for assessments conducted between July 1998 and October 1999. Although there were over 300 CBA IPI reports returned to the SEI for this time period, the Lead Assessor Requirements Checklist was a new requirement added in late 1998. Monitoring of the return of this checklist along with other required feedback forms is being enforced consistently at this time.

\subsubsection{Data Entry}

A Microsoft Access database was designed, and the data was entered manually. The SEI Lead Assessor Web Center is under development and will be available in the second quarter of 2000, so that the data can be entered directly online by the Lead Assessors. This MS Access database was designed so that existing data could be subsequently imported into the Lead Assessor Web Center database.

\subsubsection{Data Analysis}

The data was checked for consistency and corrected accordingly. Details regarding which data fields have been modified are provided where appropriate throughout this document.

The data are analyzed using Microsoft Excel pivot tables and charts, and manual counting where necessary. For various numerical data elements, where the range of values is very

Capability Maturity Model is registered in the U.S. Patent and Trademark Office. 
large, the values are grouped together to create ranges for easier analysis and visualization. For free text data, the information provided is reviewed to identify a few major categories.

\subsubsection{Data Reporting}

In this report, the results of analysis are typically presented with a histogram or pie chart, depending on which provides the most comprehensive view of the data involved. In many cases, the minimum and maximum value as well as the mode (most frequently occurring) value is highlighted. Where appropriate, the average and median values are also computed.

\subsection{Document Overview}

This document is organized based on the format of the hardcopy Lead Assessor Requirements Checklist. There are four major sections in the checklist:

- planning the assessment

- conducting the assessment

- reporting results

- additional questions

The findings for each of these major sections are presented in the chapters following. In each chapter, an analysis of the results for each question that is significant or meaningful is presented. The question as shown in the checklist is first presented, followed by a graph that provides a visual indicator, and text that describes the analysis process and results. 


\section{Planning the Assessment}

\subsection{Assessment Materials}

\begin{tabular}{|l|l|}
\hline CBA IPI Requirement & How This Assessment Was Implemented \\
\hline $\begin{array}{l}\text { Material for each assessment must be pur- } \\
\text { chased from the SEI. }\end{array}$ & $\begin{array}{l}\text { Material for this assessment was obtained via: } \\
\text { • Single kit } \\
\text { • } \quad \text { Quantity kit }\end{array}$ \\
\hline
\end{tabular}

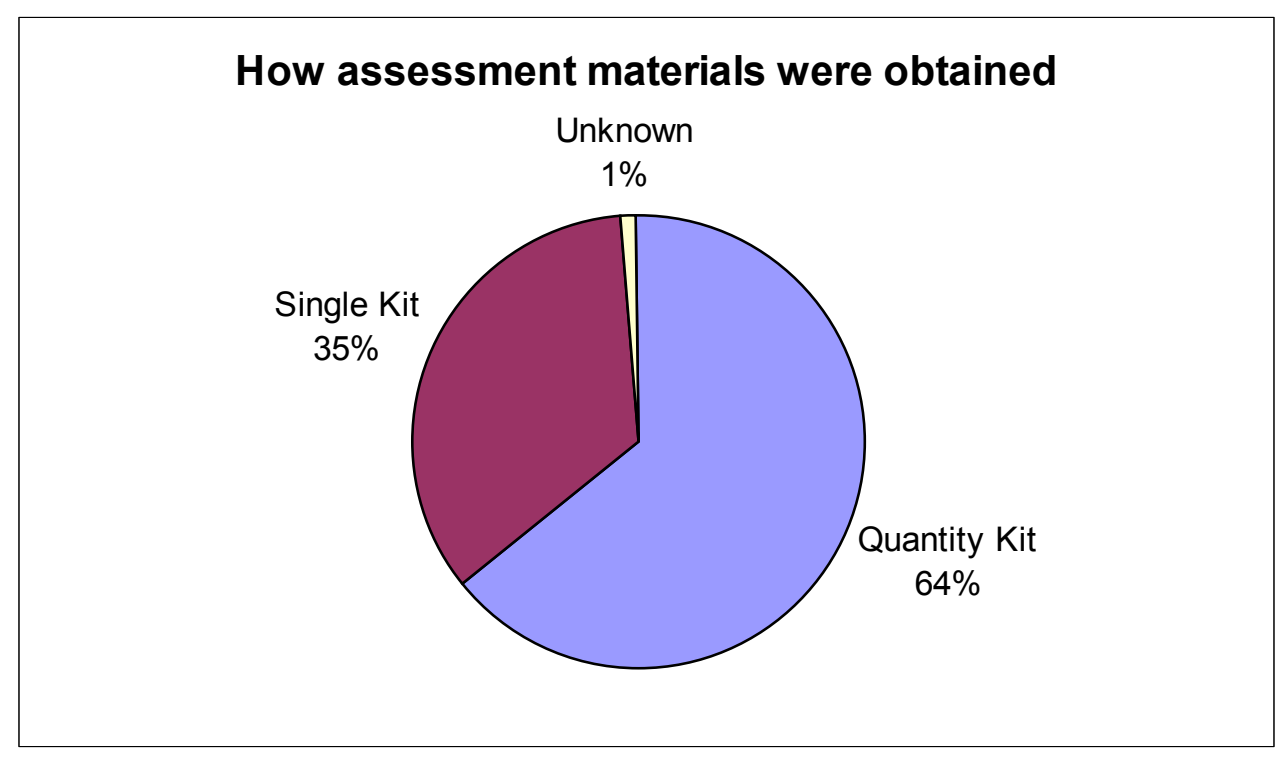

Figure 1: How Assessment Materials Were Obtained

Out of the 83 forms submitted, 53 indicated that a quantity kit was used, while 29 indicated that a single kit was purchased. One entry did not specify how the assessment materials were obtained. 


\subsection{Team Composition}

2.2.1 Team Size

\section{CBA IPI Requirement}

The team shall have 4 to 10 team members. At least one member must be from the organization being assessed.
How This Assessment Was Implemented

- Total number of team members

- Number of team members from the assessed organization

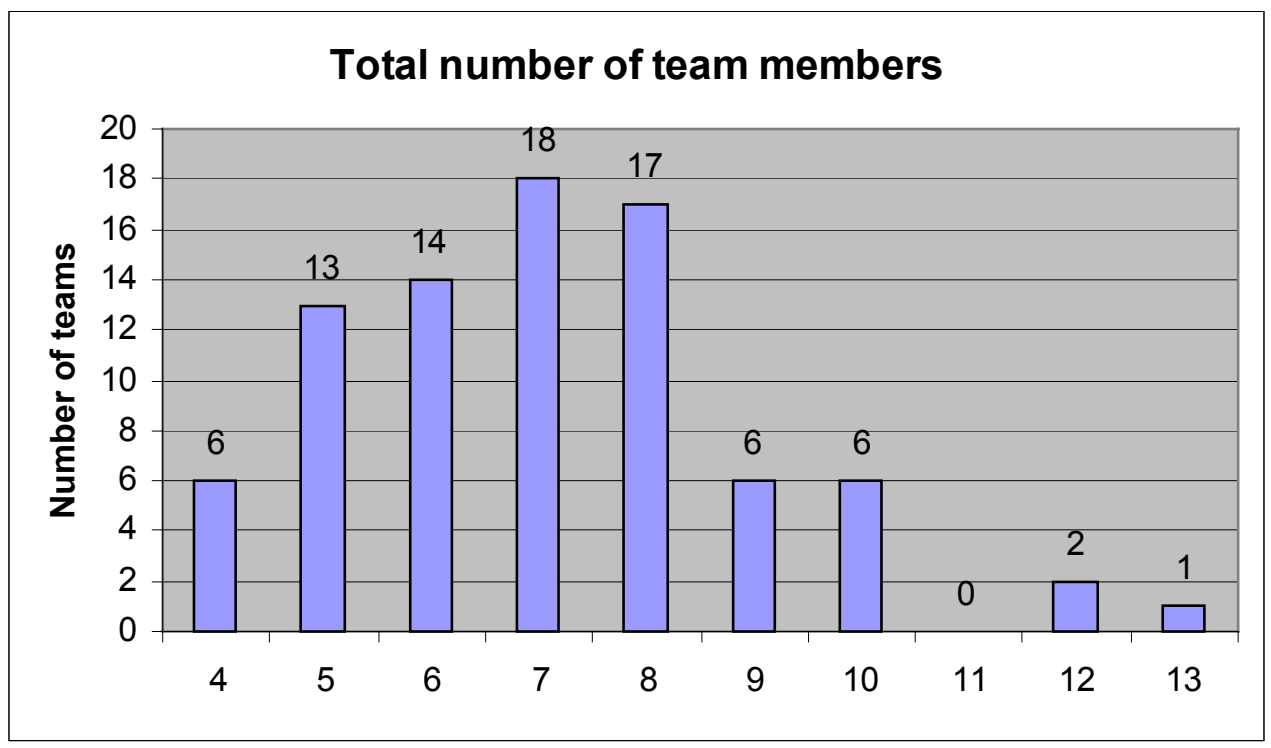

Figure 2: Total Number Of Team Members

The histogram above indicates that the team size ranges from 4 to 13 members. Three out of 83 assessments $(\sim 4 \%)$ exceeded the team size of 4 to 10 members recommended by the SEI. The average team size is seven, which is also the most frequently occurring team size (mode) as well as the median. The histogram above is skewed right indicating that there are fewer large teams ( $\geq 9$ members). 


\subsubsection{Proportion of Members from Assessed Organization}

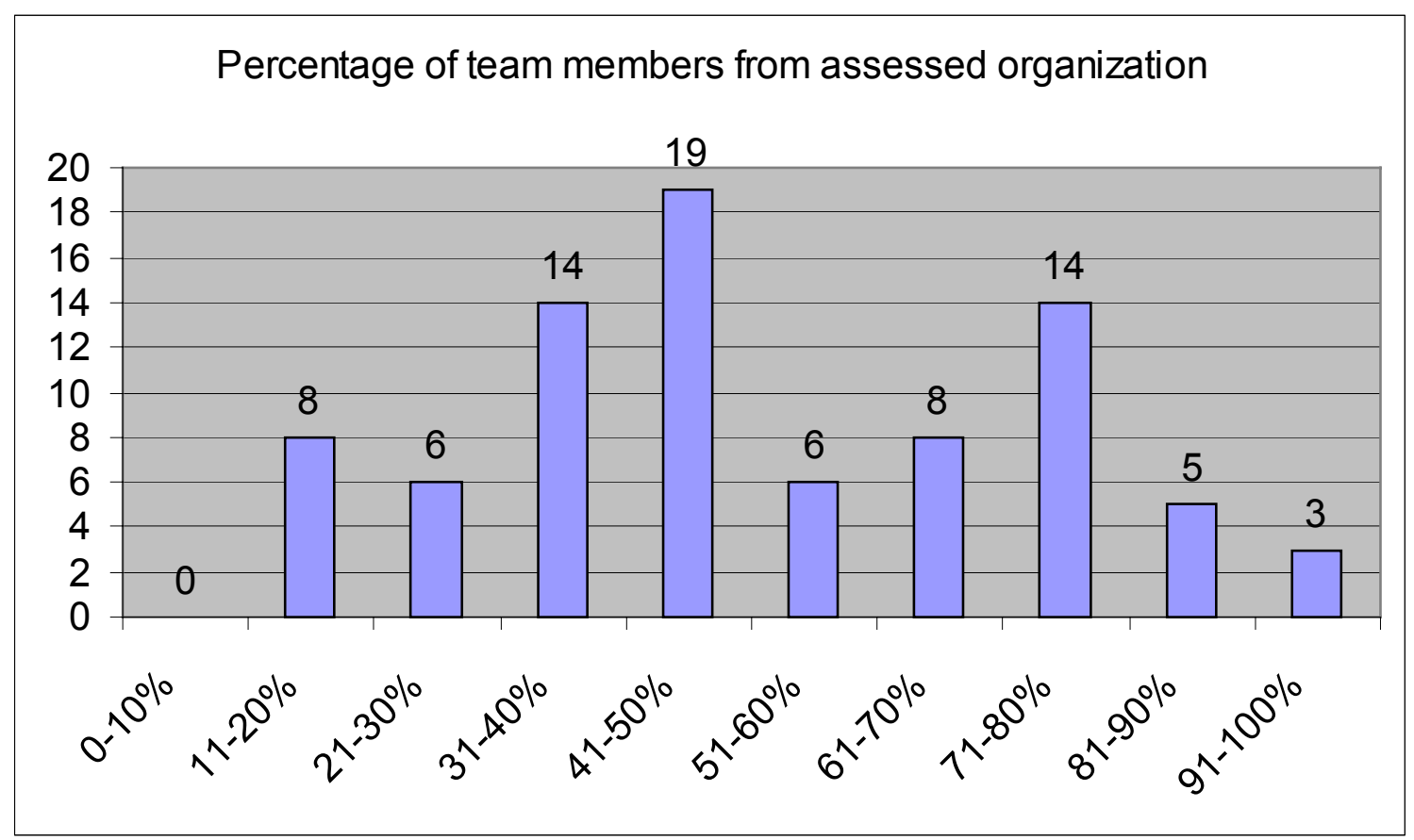

Figure 3: Proportion of Members from Assessed Organizations

The CBA IPI method requires that at least one member of the team must be from the assessed organization. This means a range of $10-25 \%$ of a team of 4 to 10 members. The distribution above indicates that all 83 teams met this requirement. There are some teams comprised of all members from the assessed organization.

\subsubsection{Team Member Selection Guidelines}

\section{CBA IPI Requirement}

Team members must meet the selection guidelines.
How This Assessment Was Implemented Upon checking credentials of assessment team members, how would you rate the team's experience level against the recommended guidelines?

(rate on a scale from 1 to 5 :

1-do not meet guidelines; 5 -exceed the guidelines) 


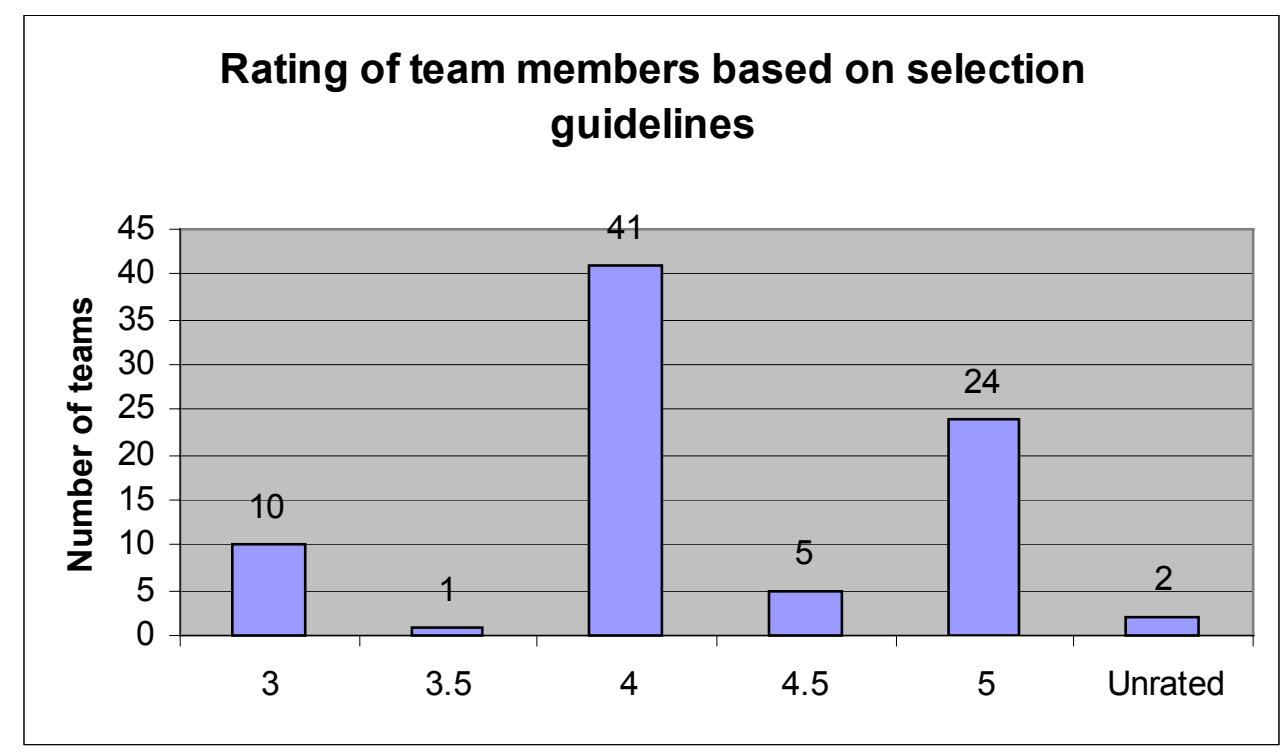

Figure 4: Rating of Team Members Based on Selection Guidelines

From Figure 4 above, it is clear that most teams do not have problems with finding team members who meet the selection guidelines. About half the teams are comprised of members who are above average, based on the guidelines (rating 4) and no teams have difficulty meeting the selection guidelines (rating 1 or 2).

\subsection{Assessed Organization}

\subsubsection{Business Goals}

\section{CBA IPI Requirement}

The assessment is discussed with the sponsor to understand the business goals.
How This Assessment Was Implemented

The business goals of the sponsor were determined to be: (please describe)

After reviewing the various business goals of the 83 assessments conducted, 10 most frequently occurring goals are identified, and all the business goals are classified under each of these goals. The following table shows the 10 most frequently occurring goals, and the number of organizations that had a business goal somewhat related. Note that each assessed organization may have specified more than one business goal.

From Figure 5, it is clear that improving quality and productivity ("Faster, better, cheaper") is the most frequently stated goal. Identifying improvement areas and attaining Level 2 Maturity are also frequent business goals. 


\begin{tabular}{|l|l|}
\hline General goal & Number \\
\hline $\begin{array}{l}\text { "Faster, better, cheaper." } \\
\text { This goal emphasizes improving quality, productivity and customer satisfaction. It is } \\
\text { probably the overall goal for software process improvement; the following, more } \\
\text { specific goals are generally based upon it. }\end{array}$ & 20 \\
\hline $\begin{array}{l}\text { Verify improvement results. } \\
\text { This goal implies that some work has been done for software process improvement, } \\
\text { and an assessment is done to measure or verify its success. This includes goals to } \\
\text { measure process improvement results and acknowledge improvements achieved. }\end{array}$ & 12 \\
\hline $\begin{array}{l}\text { Identify improvement areas / opportunities. } \\
\text { This goal focuses on identifying the strengths and weaknesses of the organization's } \\
\text { software process. }\end{array}$ & 17 \\
\hline $\begin{array}{l}\text { Establish baseline for process improvement } \\
\text { The emphasis of this goal is to establish a baseline to start improvement work so as to } \\
\text { guide tracking of software process improvement. The baseline may be related to any } \\
\text { Capability Maturity Model (CMM ) maturity level. }\end{array}$ & 14 \\
\hline Attain Level 2 Maturity & 17 \\
\hline Attain Level 3 Maturity & 7 \\
\hline Attain Level 4 or 5 Maturity & 2 \\
\hline Generate management and staff support for software process improvement & 2 \\
\hline Meet contractual requirement & 2 \\
\hline $\begin{array}{l}\text { Unknown } \\
\text { The business goal is not stated or reference is made to another document. }\end{array}$ & 12 \\
\hline
\end{tabular}

CMM is registered with the U.S. Patent and Trademark Office. 


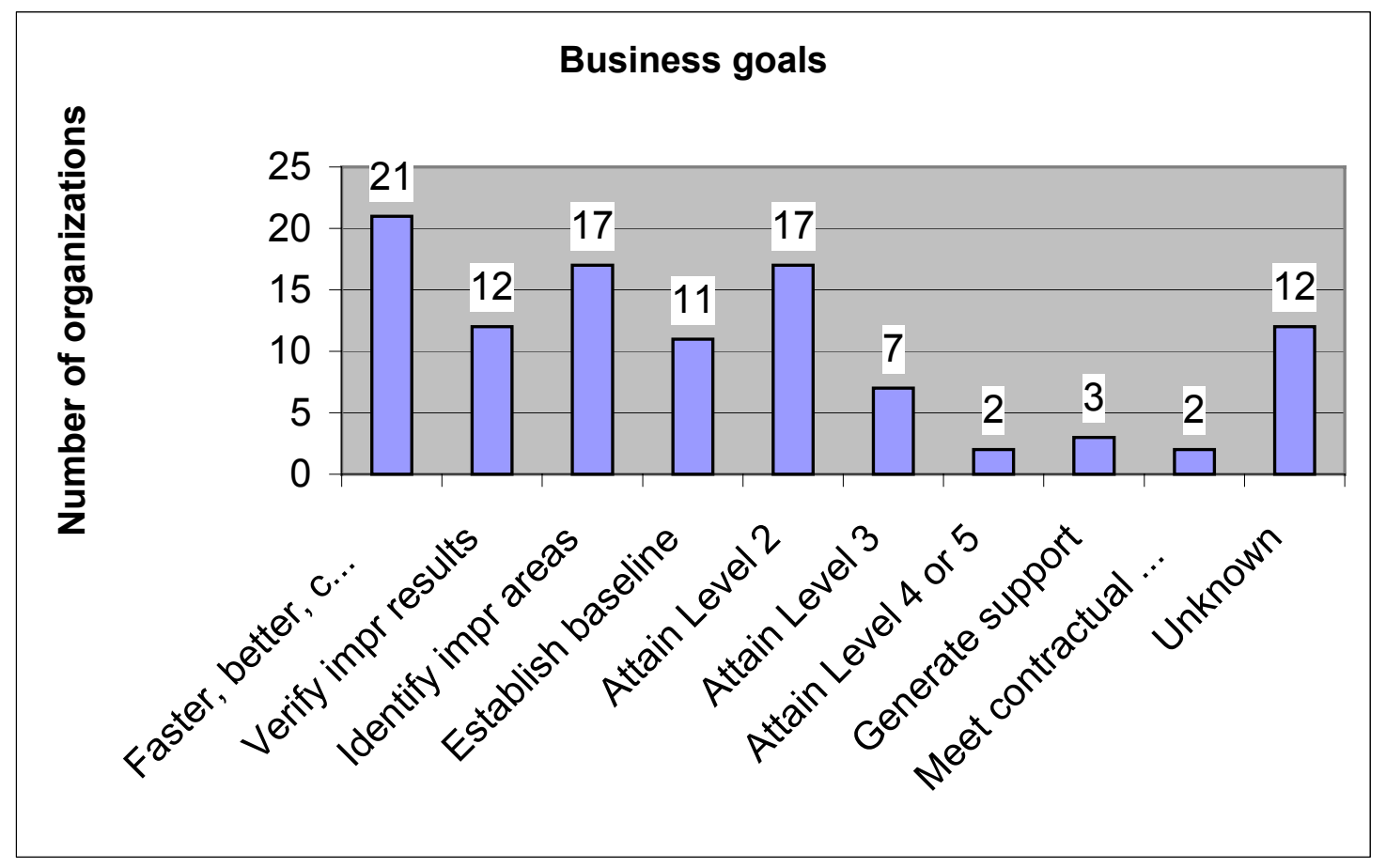

Figure 5: Business Goals

\subsubsection{Organization Size}

\section{CBA IPI Requirement}

The organization scope including selected projects and participants must be determined.
How This Assessment Was Implemented

There are __ persons in this organization with technical and managerial responsibilities for software development.

The organization scope is determined to be: 


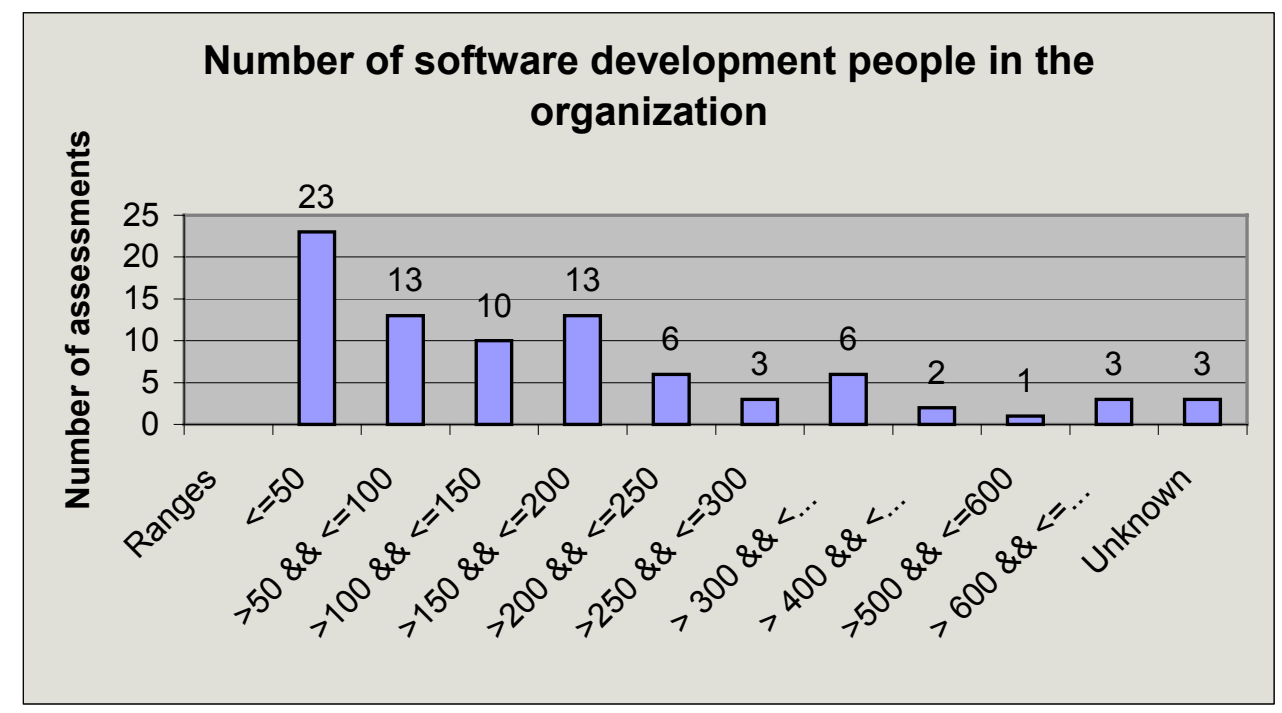

Figure 6: Number of People in the Organization

The number of people in the assessed organization with technical and managerial responsibilities for software development range from a minimum of 5 people to a maximum of 934 people in the 83 assessments performed. The above figure shows the number of organizations that fall into each range of organization size. More than half the assessed organizations have 150-or-fewer people who have technical and managerial responsibilities for software development.

\title{
2.3.3 CMM Scope
}

\section{CBA IPI Requirement}

The CMM scope (KPAs to be examined) must be determined.

\author{
How This Assessment Was Implemented \\ The CMM scope (KPAs to be examined) is de- \\ termined to be: \\ Level 2: RM, SPP, SPTO, SSM, SQA, SCM \\ Level 3: OPF, OPD, TP, ISM, SPE, IC, PR \\ Level 4: QPM, SQM \\ Level 5: DP, TCM, PCM
}

Responses to this question in the Lead Assessor Requirements Checklist may be classified into the following categories:

- Level 2 only (without SSM)

- Level 2 only (with SSM)

- Level 2 (without SSM) + Level 3

- Level 2 (with SSM) + Level 3 This includes those organizations that selected all of the KPAs in Level 2 including Software Subcontract Management (SSM), and some or all of the KPAs from Level 3. No KPAs from Levels 4 or 5 were selected. 
- Level $2+$ Level $3+$ Level 4

This includes those that selected all of the KPAs in Level 2 (with or without SSM), some or all the KPAs from Level 3, and all KPAs from Level 4. No KPAs from Level 5 were selected.

- $\quad$ Level $2+$ Level $3+$ Level $4+$ Level 5

This includes those that selected all of the KPAs in Level 2 (with or without SSM), some or all the KPAs from Level 3, and all KPAs from Level 4 and Level 5.

Figure 7 below shows the number of assessed organizations with CMM scope in each of the above categories. Almost $40 \%$ of the assessed organizations selected all KPAs from Level 2 (excluding SSM) and some or all KPAs from Level 3 as their CMM scope. It is also noted that among the organizations whose CMM scope included Level 2 and/or Level 3 only, about one-third determine Software Subcontract Management (SSM) to be not applicable.

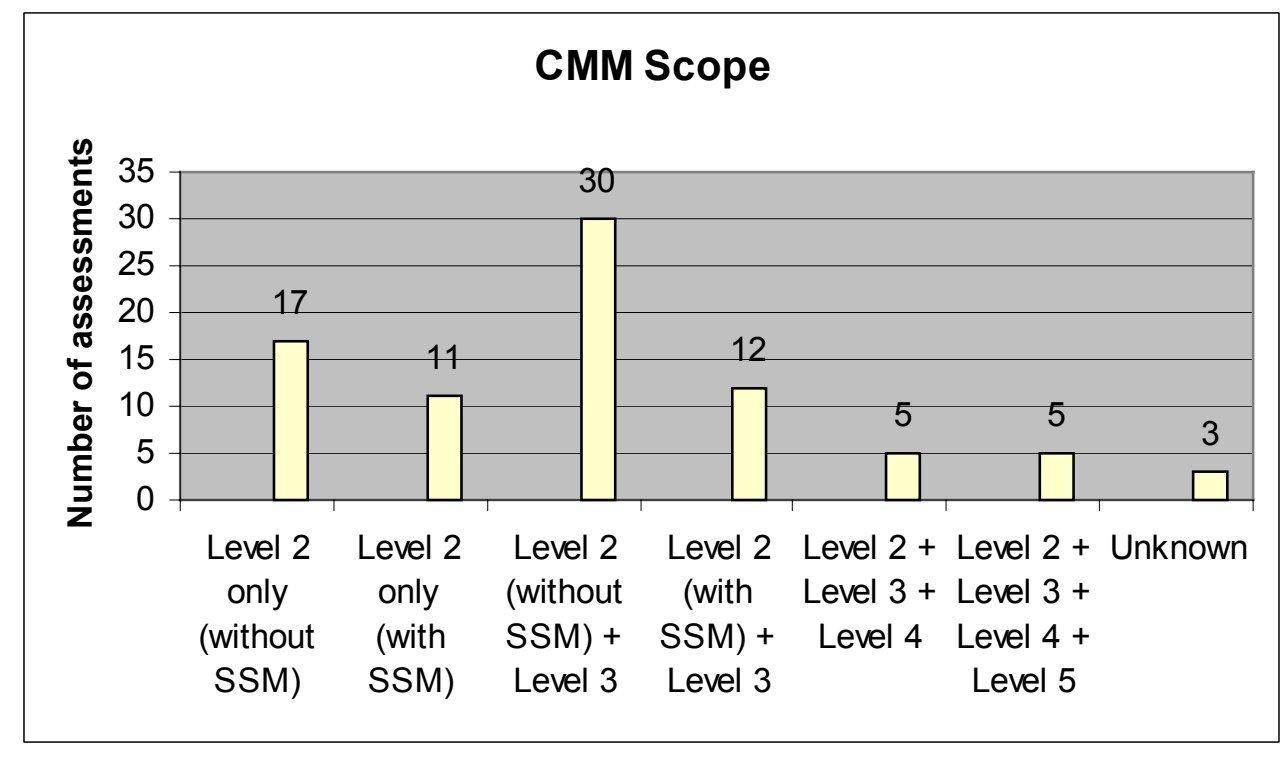

Figure 7: CMM Scope

Level 2 KPAs were typically all selected with or without SSM. Level 4 and 5 KPAs were typically all selected when the level was included in the CMM scope. Level 3 has the greatest variation in terms of the KPAs selected. Figure 8 provides a breakdown of the KPAs that are selected in Level 3. The last column reflects the number of organizations with a CMM scope that includes all of the KPAs in Level 3. It is not to be compared with the other columns.

The histogram indicates that Integrated Software Management (ISM) is the least frequently selected KPA in Level 3, followed by Intergroup Coordination (IC) and Software Product Engineering (SPE). 


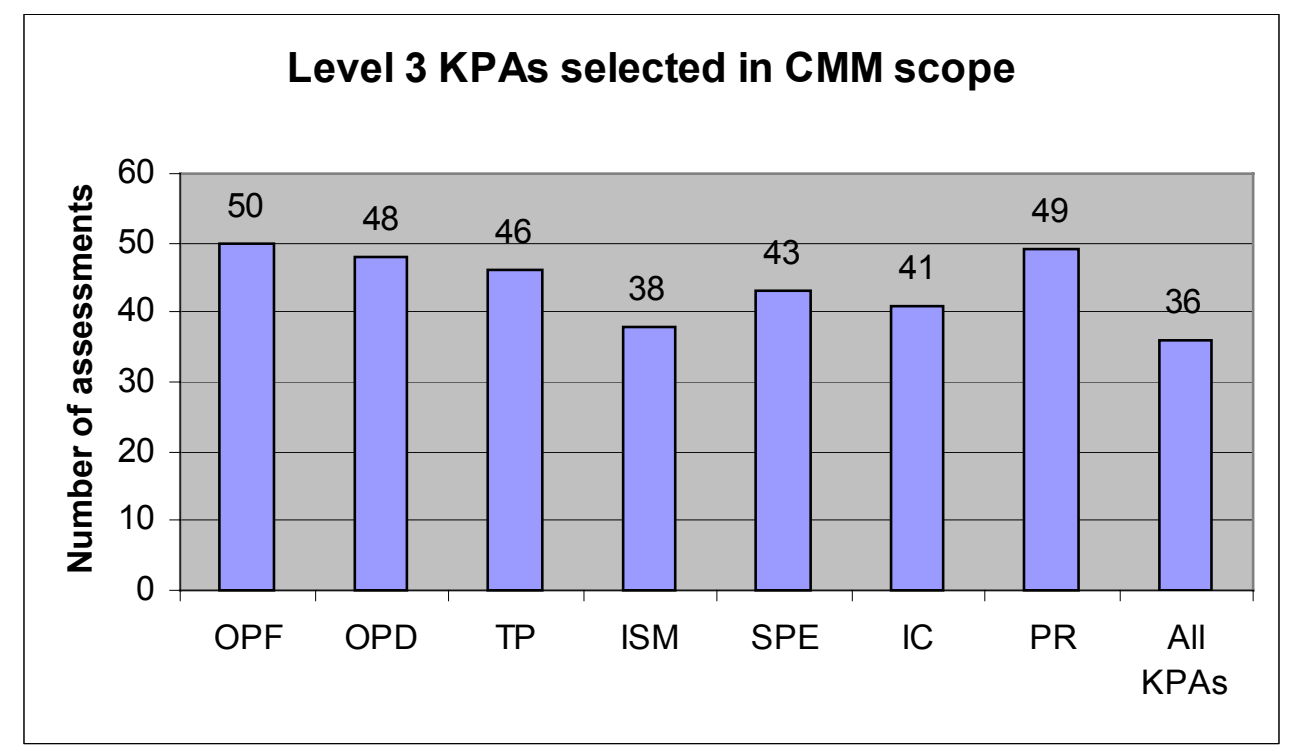

Figure 8: Level 3 KPAs selected in CMM Scope

\subsection{Training}

\subsubsection{CMM Training}

\begin{tabular}{|l|l|}
\hline CBA IPI Requirement & How This Assessment Was Implemented \\
\hline $\begin{array}{l}\text { All team members must receive the SEI In- } \\
\text { troduction to CMM course or equivalent }\end{array}$ & $\begin{array}{l}\text { Was the SEI Introduction to CMM course used in } \\
\text { its entirety? yes no } \\
\text { If not, what CMM course was used (e.g., source, } \\
\text { instructor, date) }\end{array}$ \\
\hline
\end{tabular}

For this question in the Lead Assessor Requirements Checklist, there seems to be some confusion in the responses. Some responded with a "yes" to the question, and yet provided a course name that is not the SEI Introduction to CMM course. Hence, the data was reviewed and corrected for consistency. A new data value, "some", was also introduced in addition to the "yes" or "no" answer to accommodate entries where both "yes" and "no" were indicated due to some team members who had SEI Introduction to CMM training, but others who had other training. 


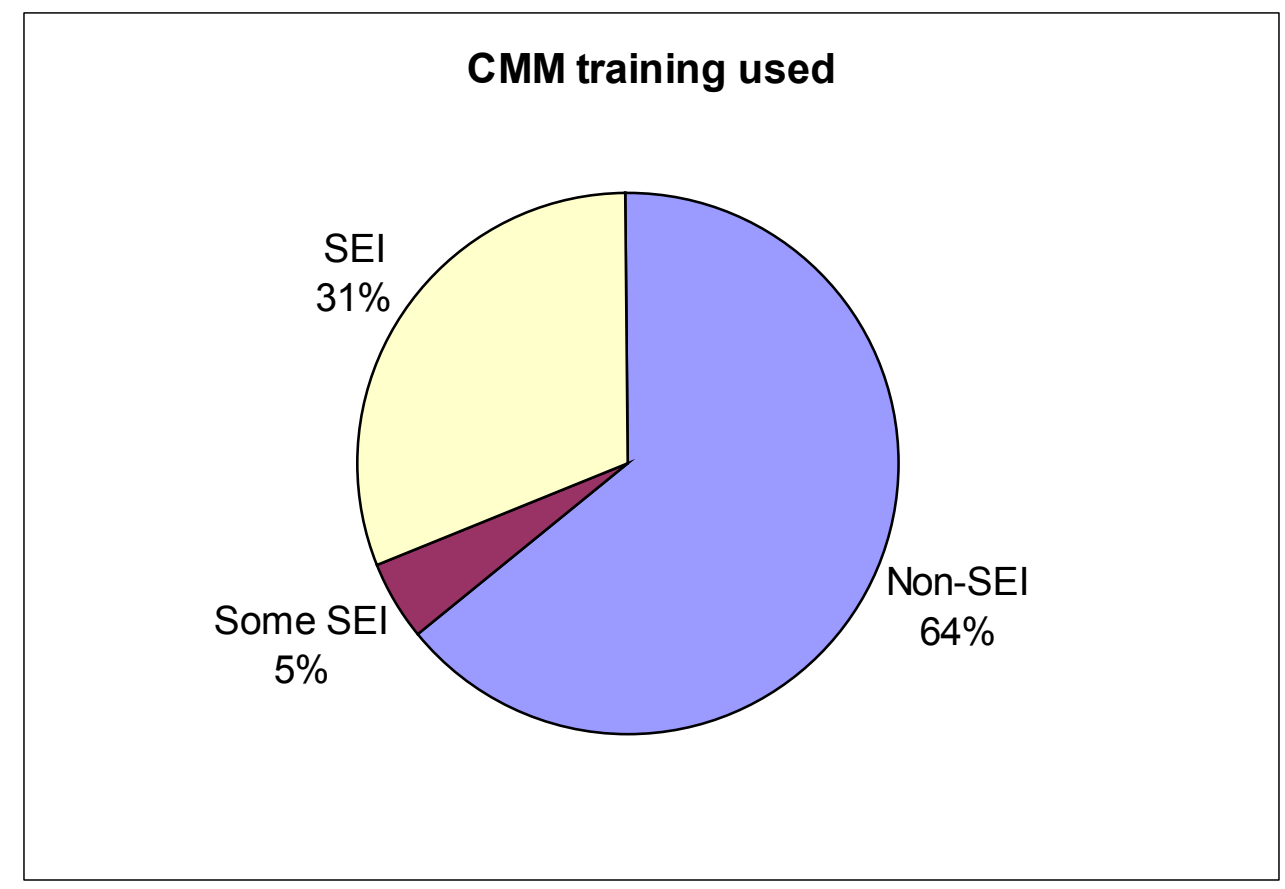

Figure 9: $\quad C M M$ Training Used

The pie chart above shows the distribution of teams that had the SEI Introduction to CMM training, those who had other training, and those that had a combination of both. For the teams with non-SEI training, the CMM training provided is typically in-house developed courses; otherwise, it may be third-party courses, or courses taught by the Lead Assessor.

\subsubsection{CBA IPI Team Training}

\section{CBA IPI Requirement}

All team members must receive the SEI CBA IPI Team Training course.

\section{How This Assessment Was Implemented}

Was the SEI CBA IPI Team Training used in its entirety? yes no. If no, describe modifications:

Dates and time (number of hours) allocated for Team Training:

Planned:

Actual:

Did you supplement the Team Training with your own material? yes no. If yes, what areas did you supplement?

How many team members participated in CBA IPI Team Training? If any team members were waived from team training, please indicate the Lead Assessor and the dates that this team member received prior CBA IPI Team Training: Team members waived (names, prior training, instructor \& dates): 


\subsubsection{Time Spent in CBA IPI Team Training}

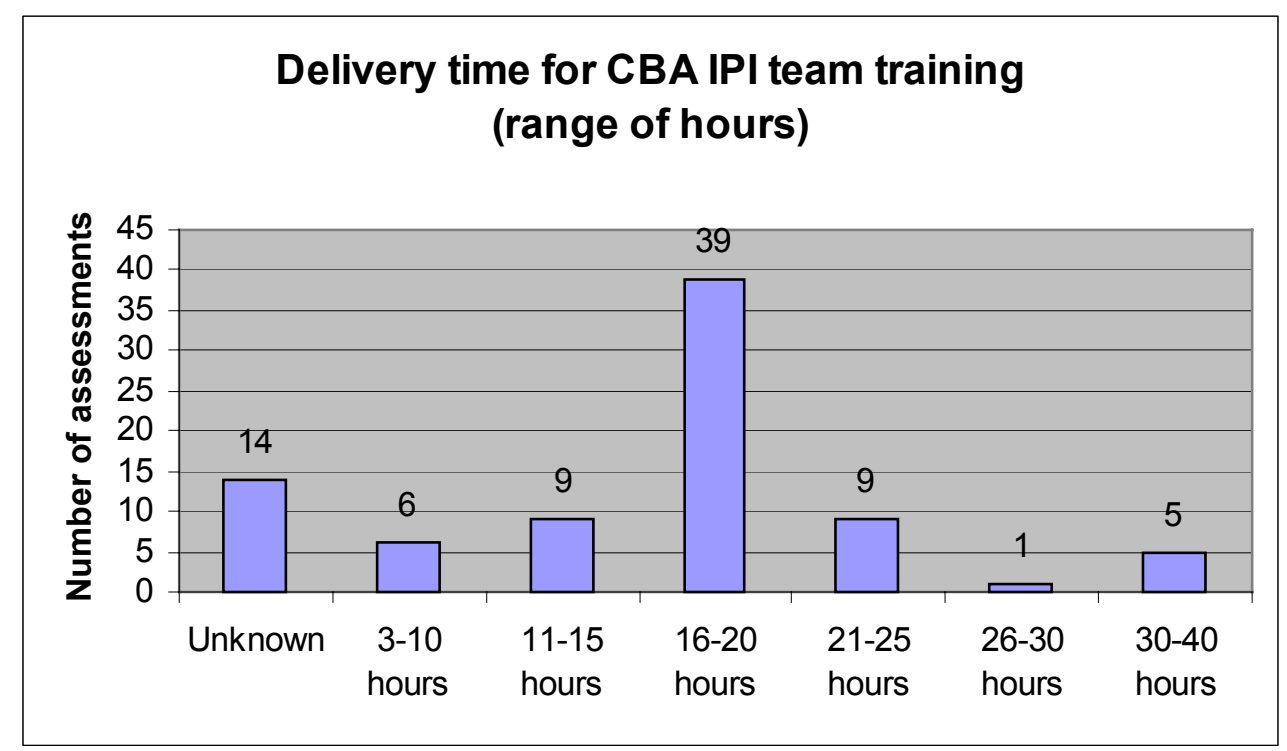

Figure 10: Delivery Time for CPA IPA Team Training

The number of hours spent on CBA IPI team training ranged from 3 hours to 40 hours. The various delivery times are grouped into ranges shown in Figure 10. Most teams fall under the 16-20 hours range. The complete data indicates that 21 teams have team training consuming 20 hours, and 11 teams have training that consumes 16 hours. 


\subsubsection{Team Members Waived from Team Training}

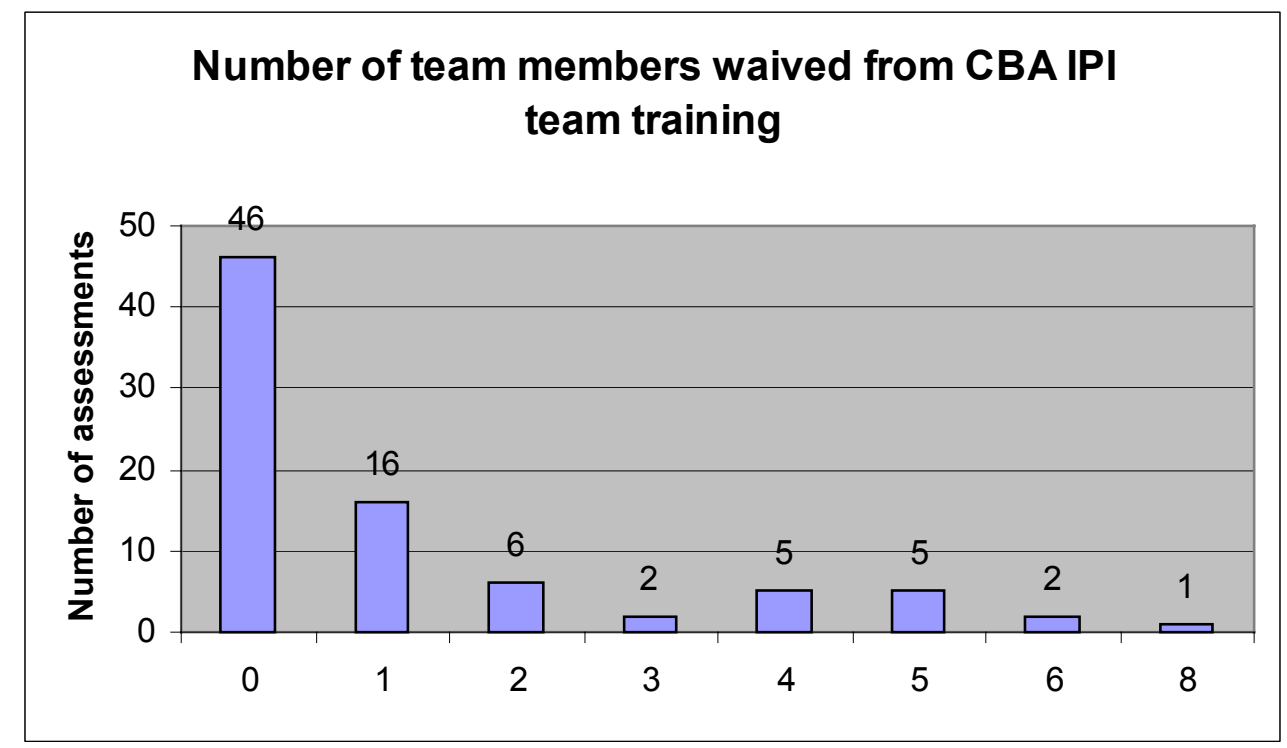

Figure 11: Number of Team Members Waived from CBA IPI Team Training

The number of team members waived from CBA IPI team training was obtained by subtracting the number who participated in team training from the team size. In four of the cases this produced a negative number; these involved people who were not part of the team but who participated in the team training. For such cases, it is assumed that the number of people who participated in the team training included all the team members and the number waived is zero. The histogram above indicates that most teams (55\%) do not have any team members waived from CBA IPI team training. About $20 \%$ of the teams have one person waived and $25 \%$ of the teams have two or more persons waived. 


\subsubsection{Supplementary Materials}

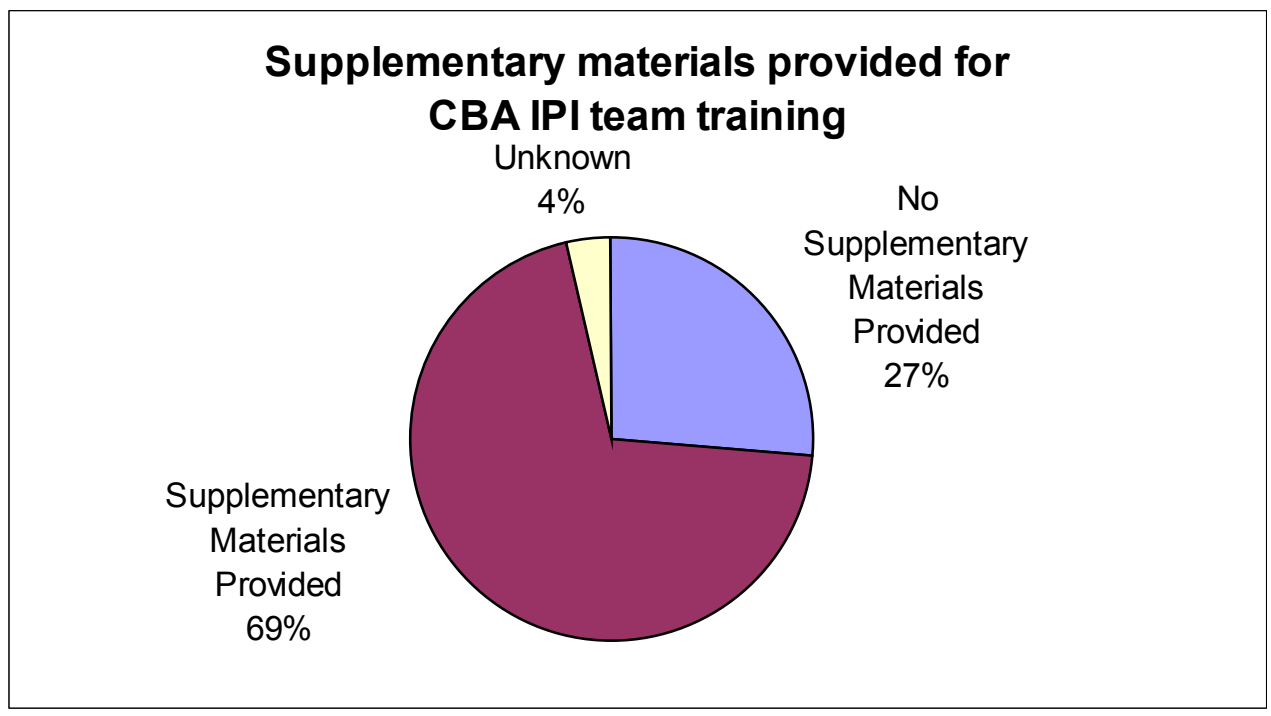

Figure 12: Supplementary Materials Provided for CBA IPI Team Training

Of the 83 assessments reported, 22 Lead Assessors did not use any supplementary materials for team training, while 58 Lead Assessors did.

Classifying the types of supplementary materials used will be useful in identifying the areas of improvement for the CBA IPI Team Training. Out of those who did provide supplementary materials, the types of supplementary materials provided can be classified as follows:

1. planning and team building

2. automation tools (including electronic worksheets)

3. KPA worksheets and other templates

4. document review techniques/exercises

5. interview-related techniques/exercises

6. consolidation techniques/exercises

7. exercises, examples and case studies (usually, related to the assessed organizations)

8. rating/scoring system

9. materials with respect to small organizations

10. unknown (either unspecified or too general to be categorized)

The distribution of the types of supplementary materials used is shown in Figure 13 below. Automation tools and exercises are the most frequent types of supplements to the team training. This is to be expected, since various organizations have their own ways of automating processes, and it is useful to tailor exercises to the context and data of the assessed organization. The next most frequent types of supplementary materials used are in the areas of planning and team building, consolidation and interview techniques/exercises. 


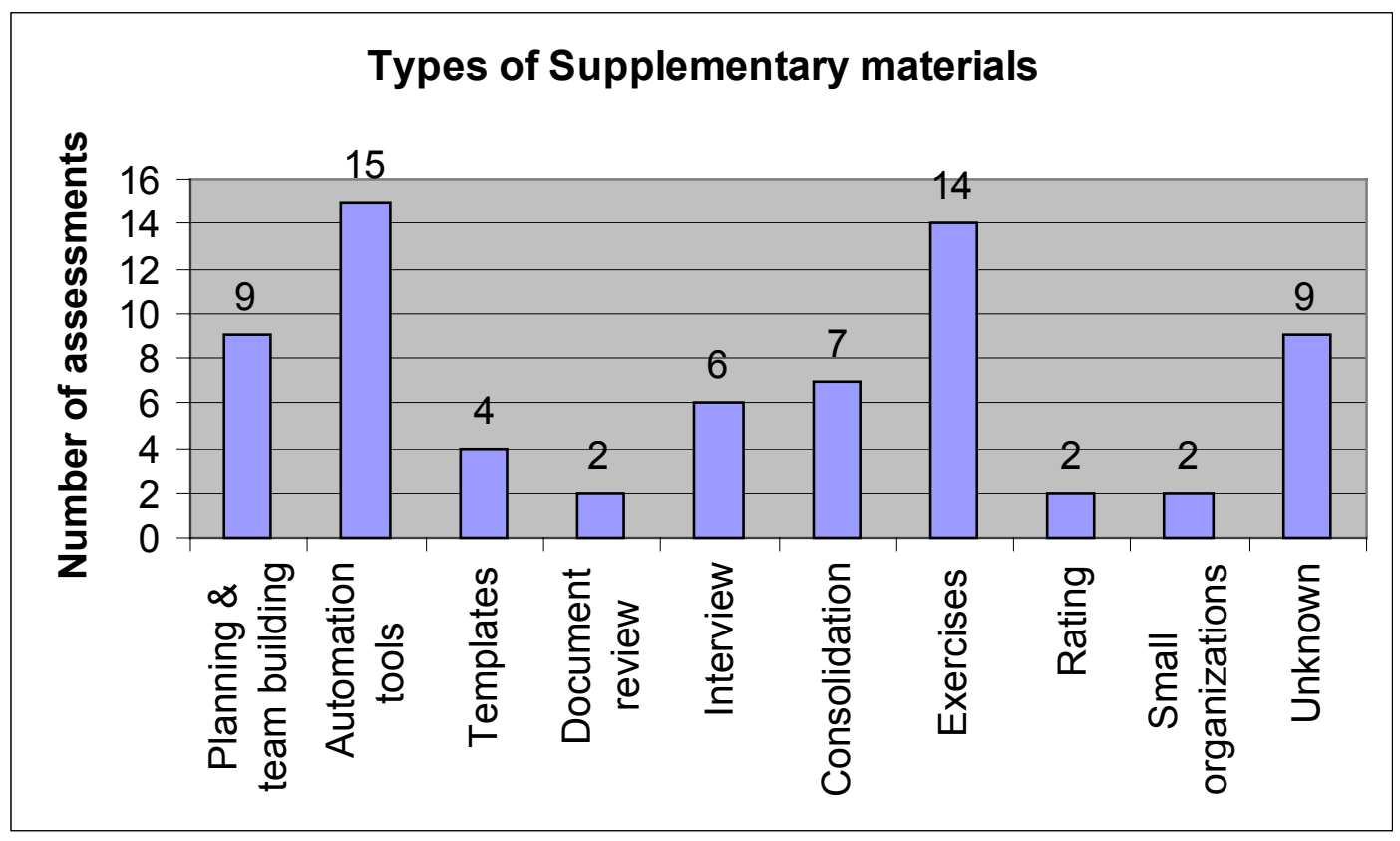

Figure 13: Types of Supplementary Materials 


\section{Conducting the Assessment}

\subsection{Maturity Questionnaires}

\begin{tabular}{|l|l|}
\hline CBA IPI Requirement & How This Assessment Was Implemented \\
\hline $\begin{array}{l}\text { Administer maturity questionnaires for at } \\
\text { least the project leaders from the selected } \\
\text { projects. }\end{array}$ & How many questionnaires were administered? \\
\hline
\end{tabular}

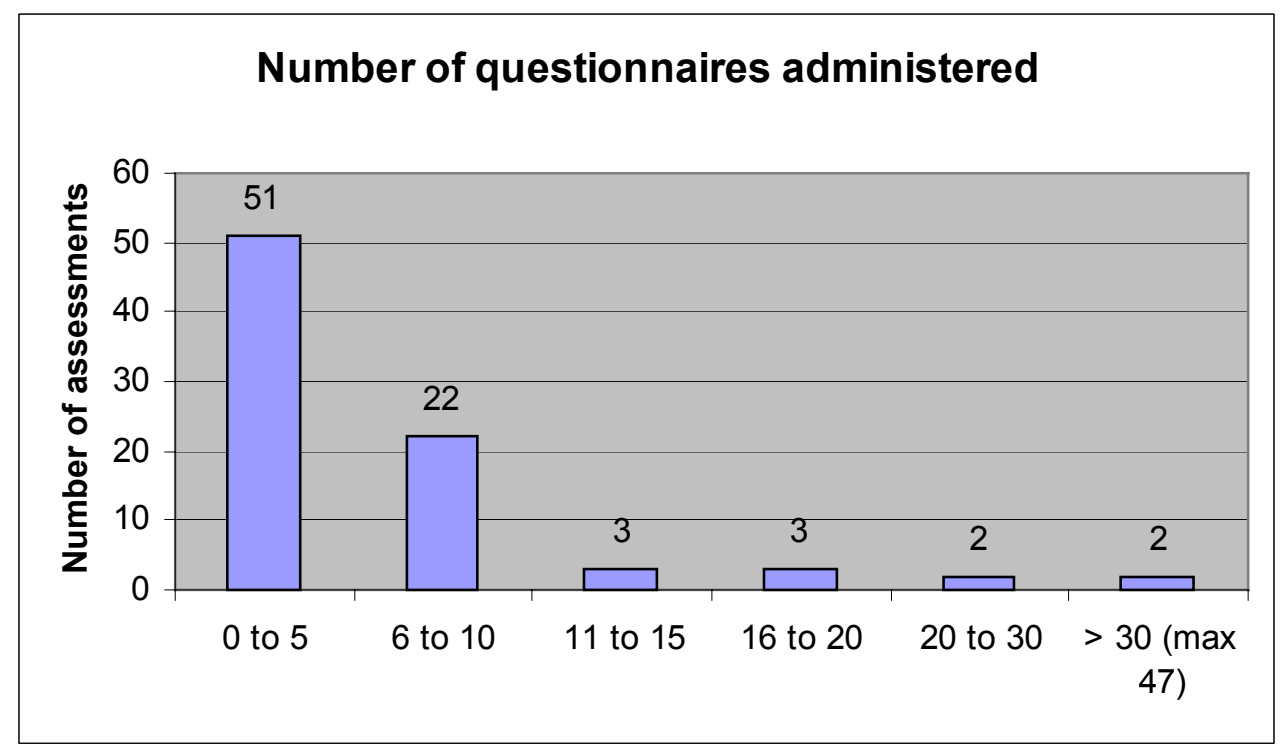

Figure 14: Number of Questionnaires Administered

The histogram above shows the range in the number of maturity questionnaires that were administered in the 83 assessments. For most assessments, one to five questionnaires are administered. Only one reported not using the questionnaire. The actual numbers range from 0 to 47 questionnaires.

According to the CBA IPI requirement, maturity questionnaires should be administered to at least the project leaders from the selected projects. 


\subsection{Interviews}

\section{CBA IPI Requirement}

Conduct interviews:

- project leaders (individual interviews)

- middle managers (group interviews)

- functional area representatives (group interviews)
How This Assessment Was Implemented

Indicate number and duration of each type of interview:

- project leaders :

- middle managers :

- functional area representatives:

- total number of interviewees:

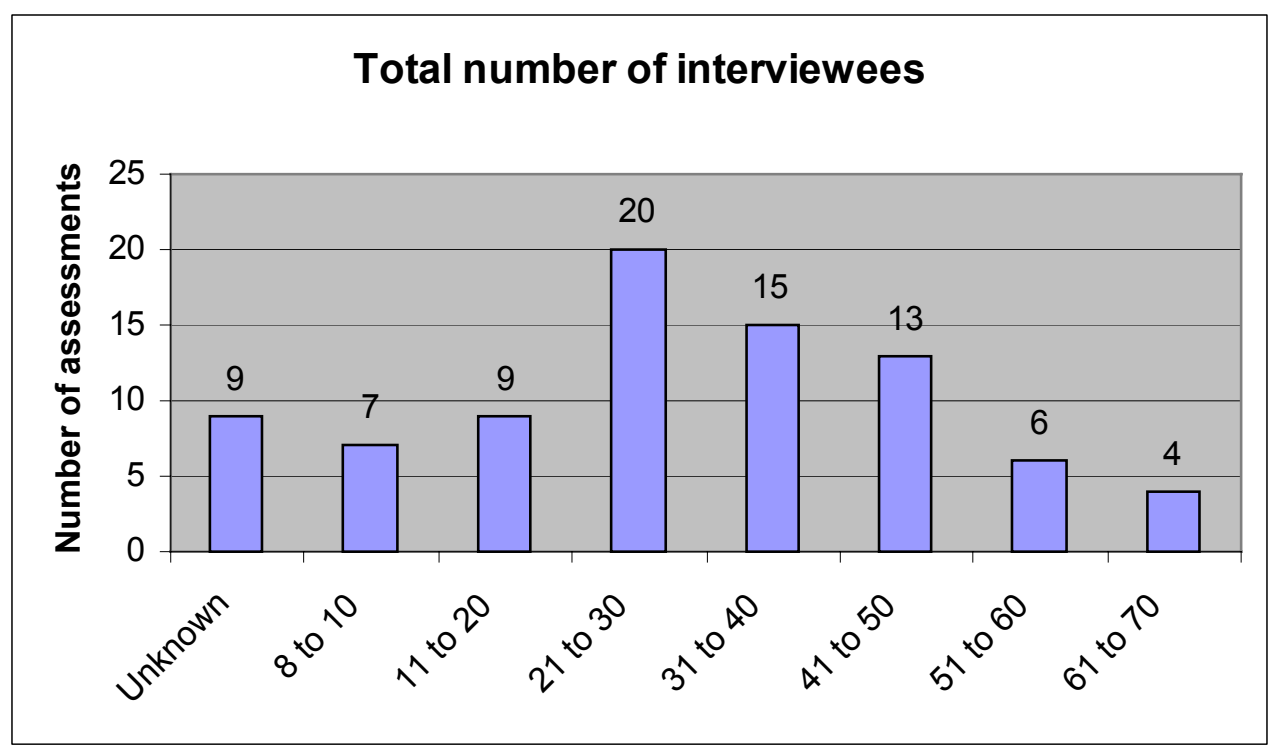

Figure 15: Total Number of Interviewees

\subsection{Documents Reviewed}

\begin{tabular}{|l|l|}
\hline CBA IPI Requirement & How This Assessment Was Implemented \\
\hline $\begin{array}{l}\text { Conduct document review at a minimum for } \\
\text { each KPA goal within the assessment scope. }\end{array}$ & $\begin{array}{l}\text { Approximately how many documents have been } \\
\text { reviewed? }\end{array}$ \\
\hline $\begin{array}{l}\text { Documentation must be examined at least for } \\
\text { each goal for each KPA within the assess- } \\
\text { ment }\end{array}$ & $\begin{array}{l}\text { Documentation was examined for: } \\
\text { each key practice }\end{array}$ \\
\hline
\end{tabular}

The two questions above are not found sequentially in the Lead Assessor Requirements Checklist. However, it's been noted that they seem repetitive, and they will be combined when the checklist is put on the Web Center. Most responses provided the same value for the total number of documents examined in these two questions. 
The number of documents reviewed ranged from 10 to 1500 in the 83 assessments analyzed. There were 13 feedback forms that did not indicate the number of documents reviewed. In some cases the documents were not counted; in others, documents were reviewed on-line and hence, were not physically counted. Most assessment teams reviewed 10 to 100 documents.

The data obtained from the above question may not be precise, as there are different ways of counting the number of documents. For example, some forms reflect the number of binders reviewed, while others provide only an estimate of how many physical documents have been reviewed. Clearer definitions are needed in order to get a consistent count of documents reviewed.

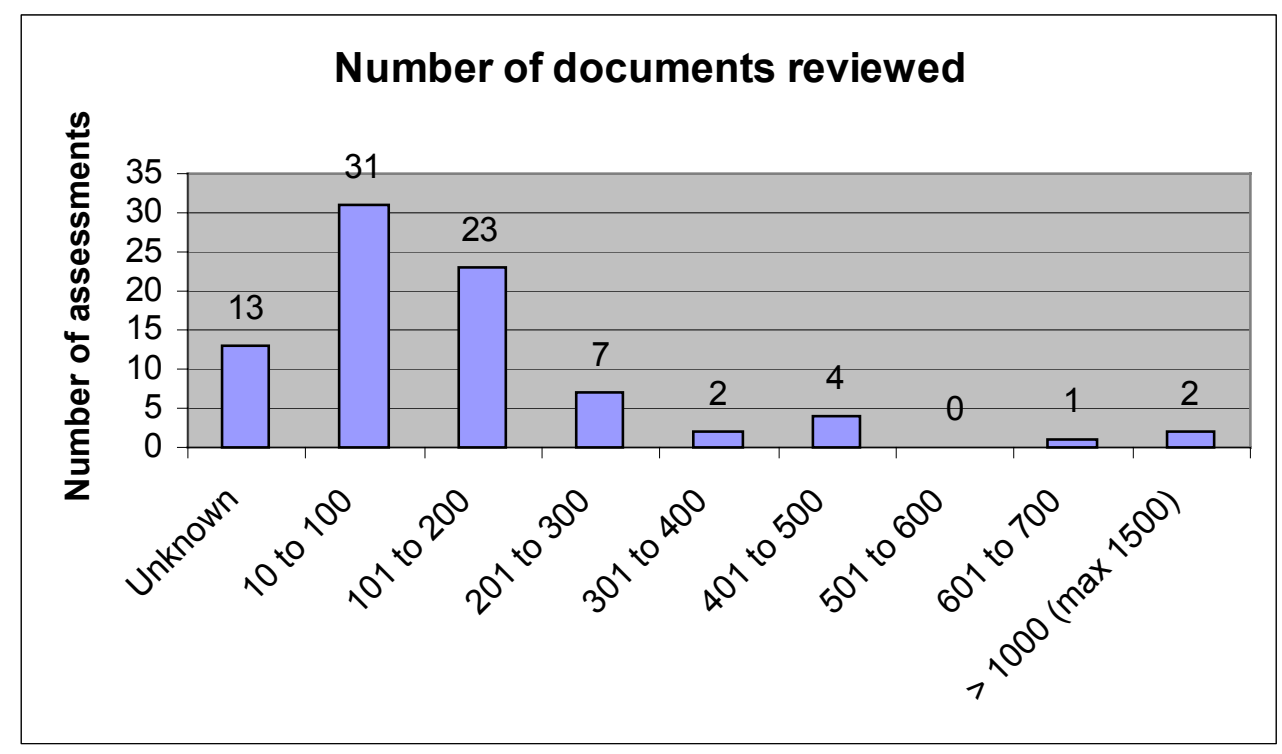

Figure 16: Number of Documents Reviewed

Although the CBA IPI method only requires documentation to be examined for each goal within the assessment scope, at a minimum, most assessments ( 77 out of 83 , or $93 \%$ ) go beyond that to the key practice level. 


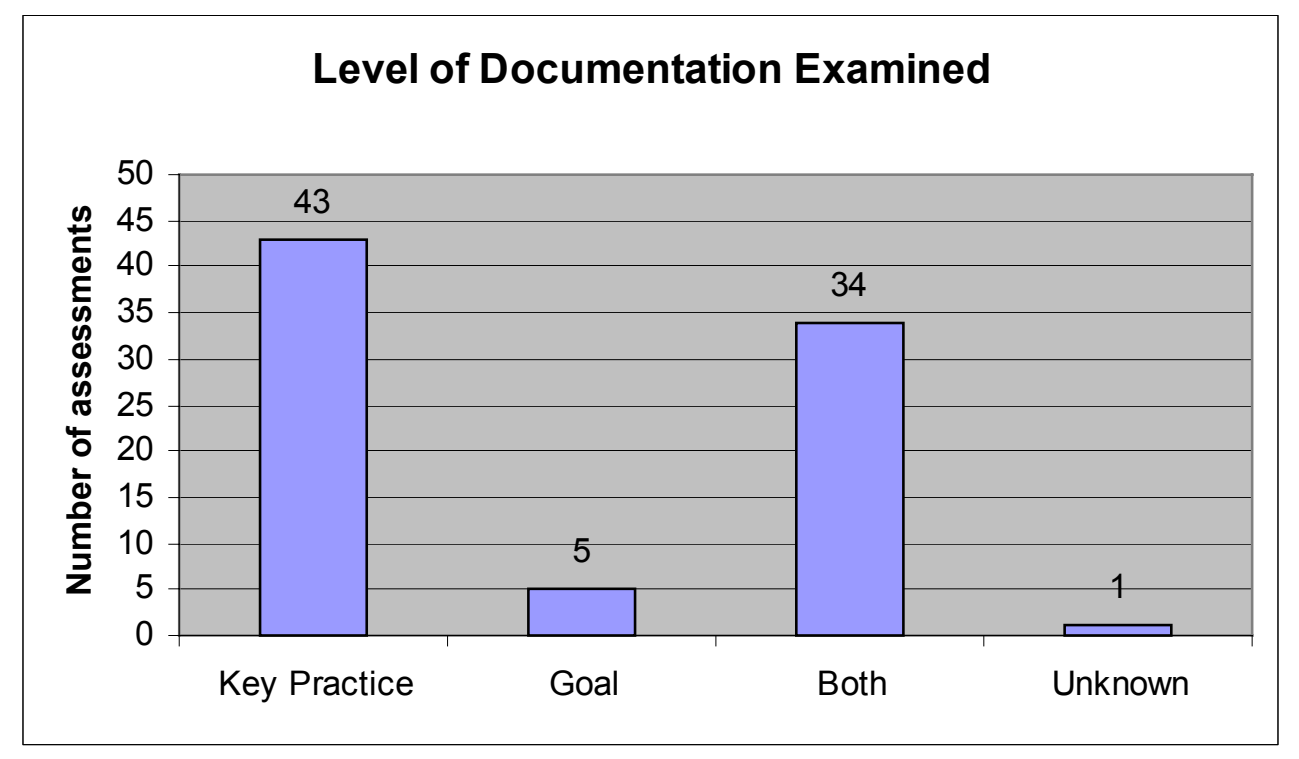

Figure 17: Level of Documentation Examined

\subsection{Level of Data Collection}

\begin{tabular}{|l|c|}
\hline CBA IPI Requirement & How This Assessment Was Implemented \\
\hline $\begin{array}{l}\text { Collect data for each key practice for each } \\
\text { KPA within the assessment scope. }\end{array}$ & Data was collected only at the goal level. \\
& Data was collected for each key practice. \\
& Data was collected for each subpractice. \\
\hline
\end{tabular}

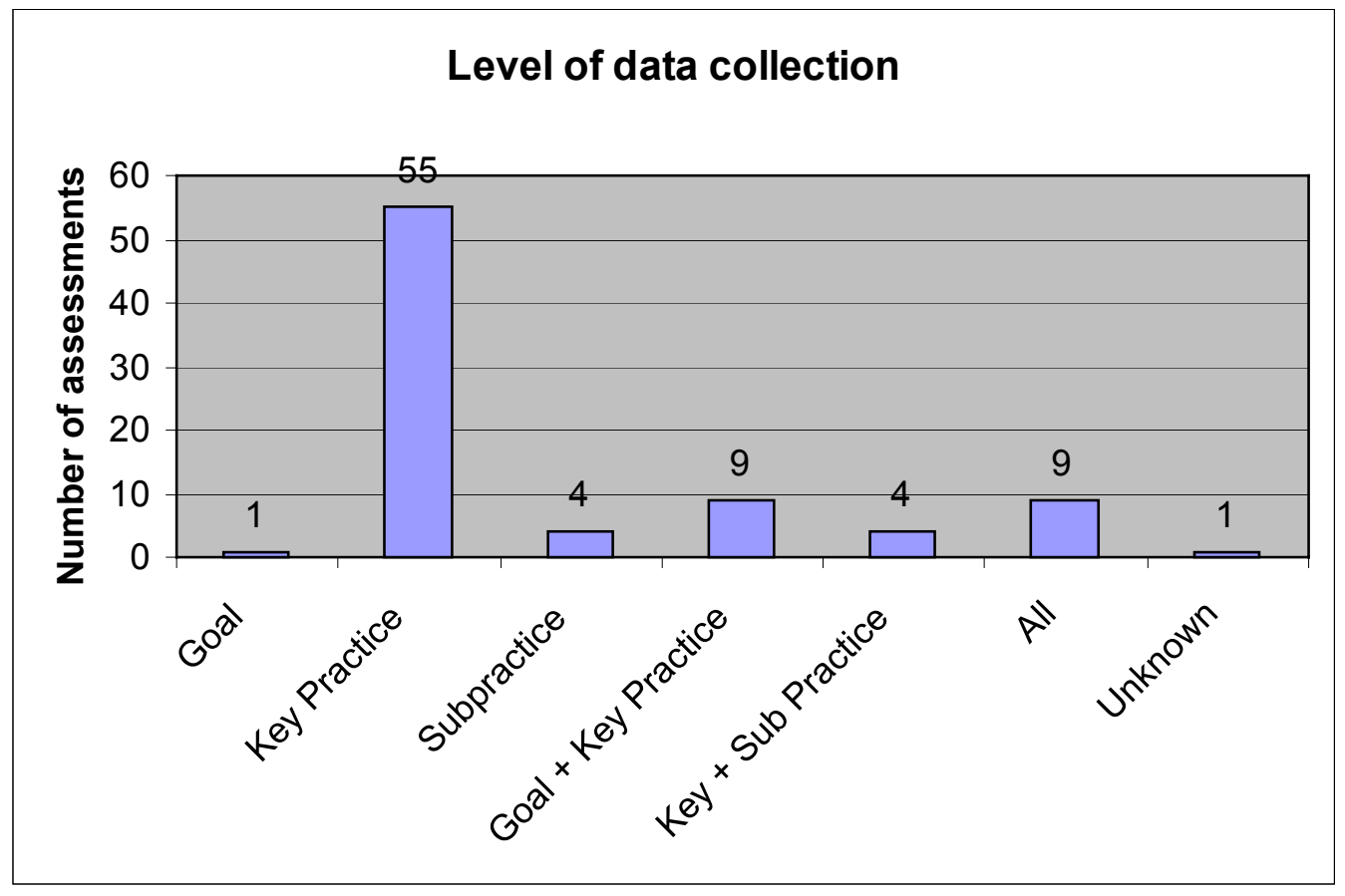

Figure 18: Level of Data Collection 
Data collection is required at the key practice level in CBA IPI. However, there has been anecdotal evidence of more stringent data collection being required at the subpractice level. This is a potential problem due to the prescriptive nature of the subpractices for which the CMM is not intended. This does not appear to be a pervasive problem since only four assessments indicate that data is collected at the subpractice level.

The histogram above shows that $98 \%$ of the 83 assessments conducted met the CBA IPI requirement for data collection for each key practice for each KPA. In only one assessment was data collected only at the goal level.

\subsection{Data Corroboration}

\section{CBA IPI Requirement}

Data was corroborated coming from at least two, independent sources at different sessions.
How This Assessment Was Implemented The entire assessment team determined that each observation was valid (accurate, corroborated, consistent).

yes no. If not, please explain:

For this question, the response was unanimously "yes" for all 83 assessments.

\subsection{Observations}

\section{CBA IPI Requirement \\ Each key practice for each KPA within the assessment scope must be determined to be sufficiently covered with observations crafted from data collected.}

\section{How This Assessment Was Implemented} number of observations were created (total). The assessment team determined sufficient coverage for each key practice for each KPA within the assessment scope. yes no. If not, please explain 


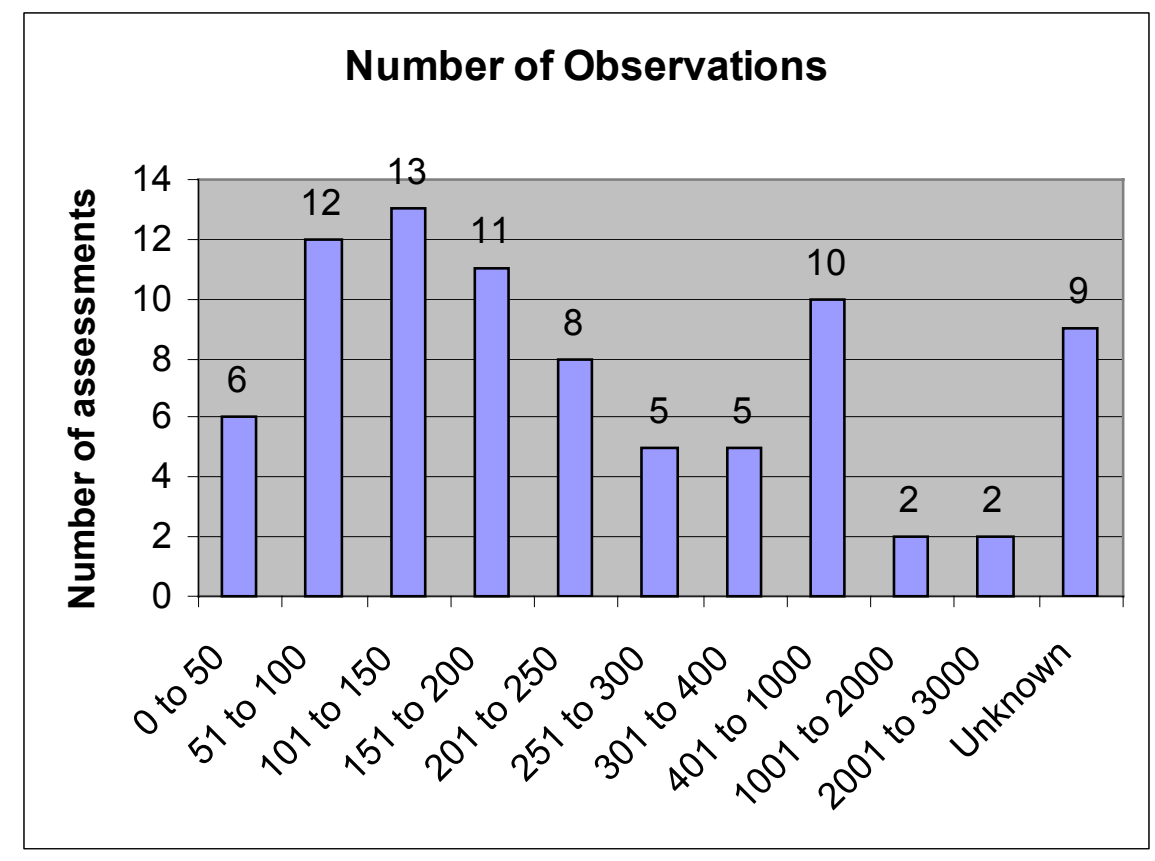

Figure 19: Number of Observations

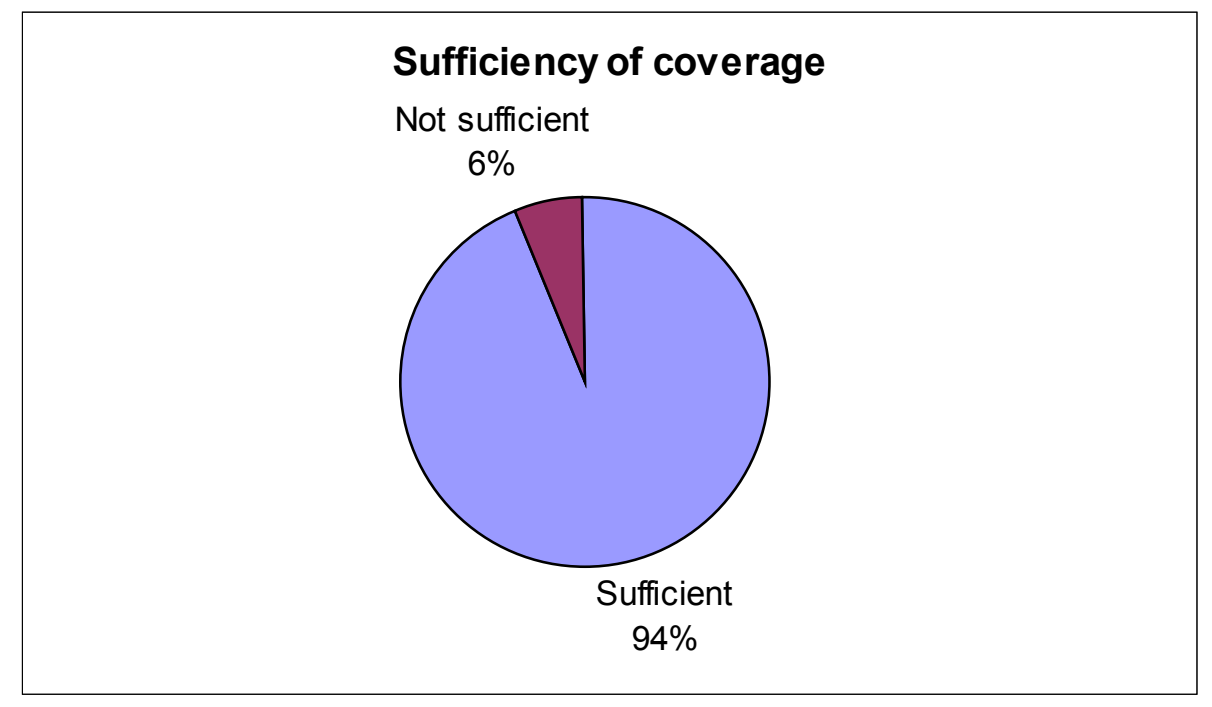

Figure 20: Sufficiency of Coverage

The total number of observations created in the 83 assessments examined ranged from 7 to 3000. The histogram above shows the distribution in ranges. Most assessments created 200 observations or less, and the average number of observations is approximately 300 .

With respect to the issue of sufficient coverage for each key practice for each KPA within the assessment scope, the pie chart above indicates only $6 \%$ (5 out of 83 assessments) had problems getting sufficient coverage. Out of these five assessments, two did not expect to get full coverage for the higher levels of maturity that were included in the assessment scope. Two 
did not have enough data to cover one specific KPA. One assessment determined a specific goal of a KPA to be not applicable and did not cover it. However, individual goals are not subject to be tailored out for non-applicability unless the entire KPA has previously been determined to be not applicable.

\subsection{Draft Findings}

\section{CBA IPI Requirement}

Conduct draft finding presentations.
How This Assessment Was Implemented number of draft findings were presented at (how many) draft finding presentations

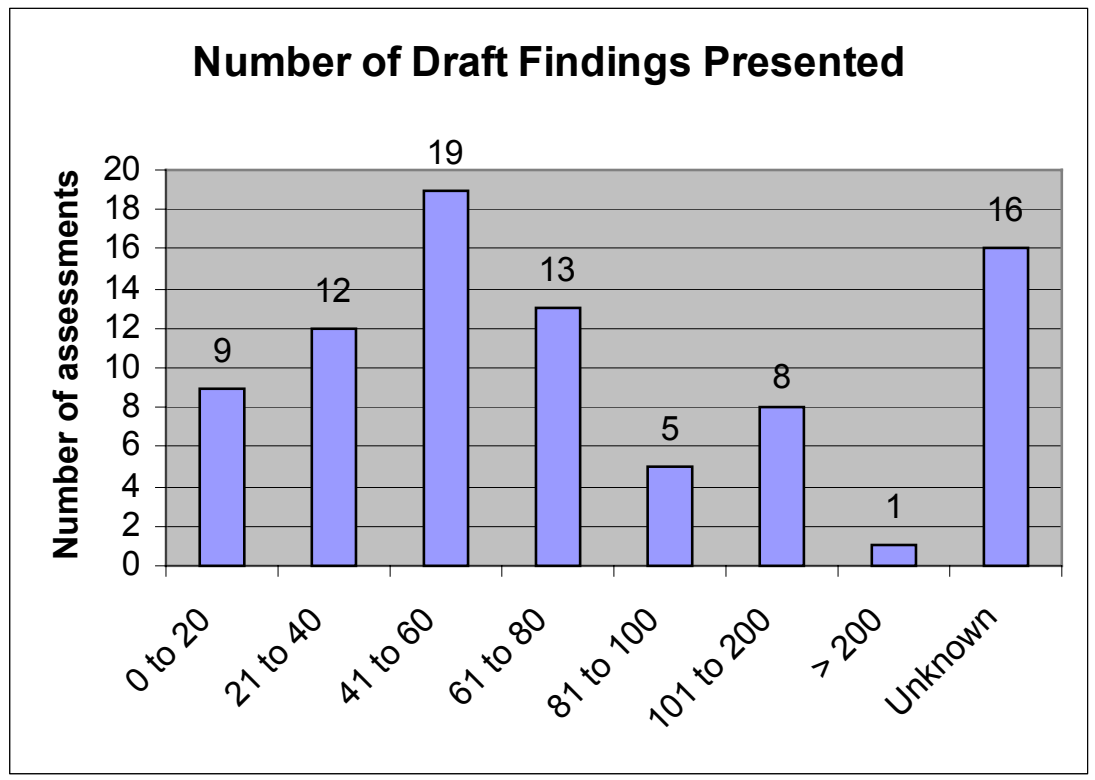

Figure 21: Number of Draft Findings Presented 


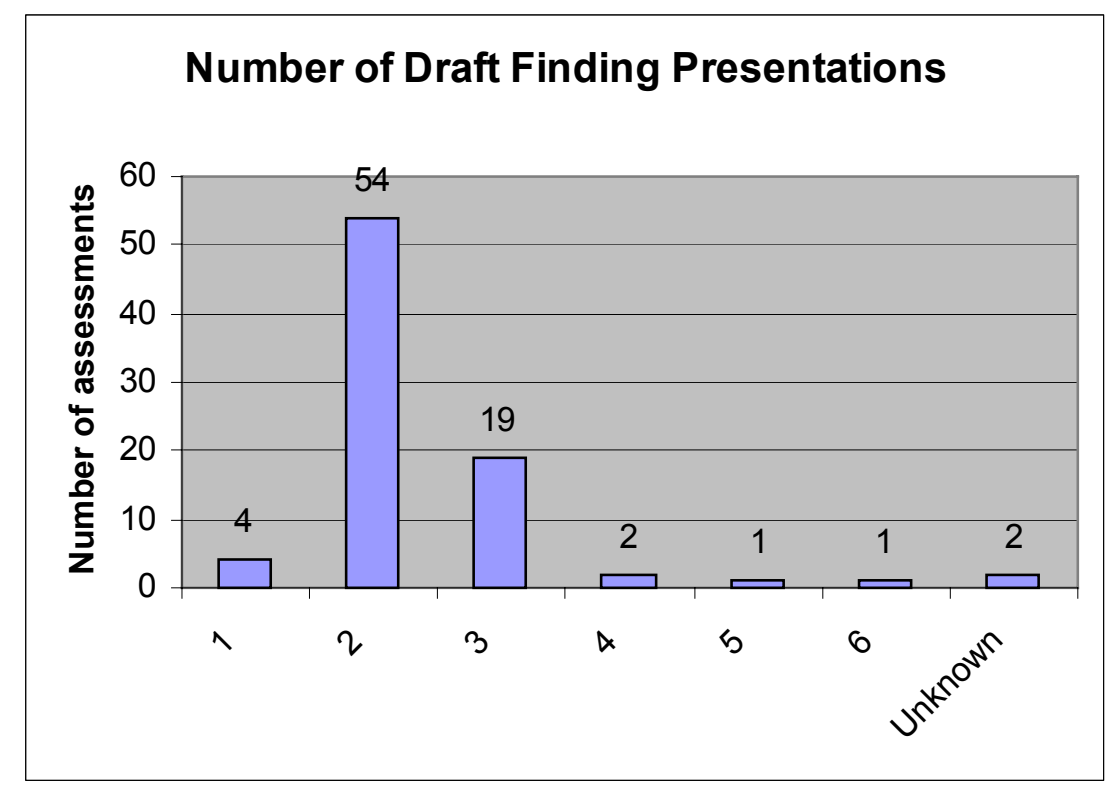

Figure 22: Number of Draft Finding Presentations

The number of draft findings ranges from 1 to 236. However, the two figures above indicate that $50 \%$ of the assessments have 60 or fewer draft findings, and that there are typically two draft-finding presentations.

\subsection{Type of Ratings}

\section{CBA IPI Requirement}

Ratings must be made based on sufficiently covered key practices mapped to the KPA goals. (maturity level rating is optional)
How This Assessment Was Implemented

Ratings were done by the assessment team for: maturity level all KPAs within the scope - except (KPAs not rated): each goal for each of above KPAs each key practice within each of above KPAs (tailoring option)

Figure 23 below presents the responses for this question. About $50 \%$ of the assessments had ratings done for the maturity level, all KPAs within the scope, and each goal for each KPA. $37 \%$ of the assessments had ratings done for all the levels (each key practice within each KPA in addition to the maturity level, KPA and goals). 


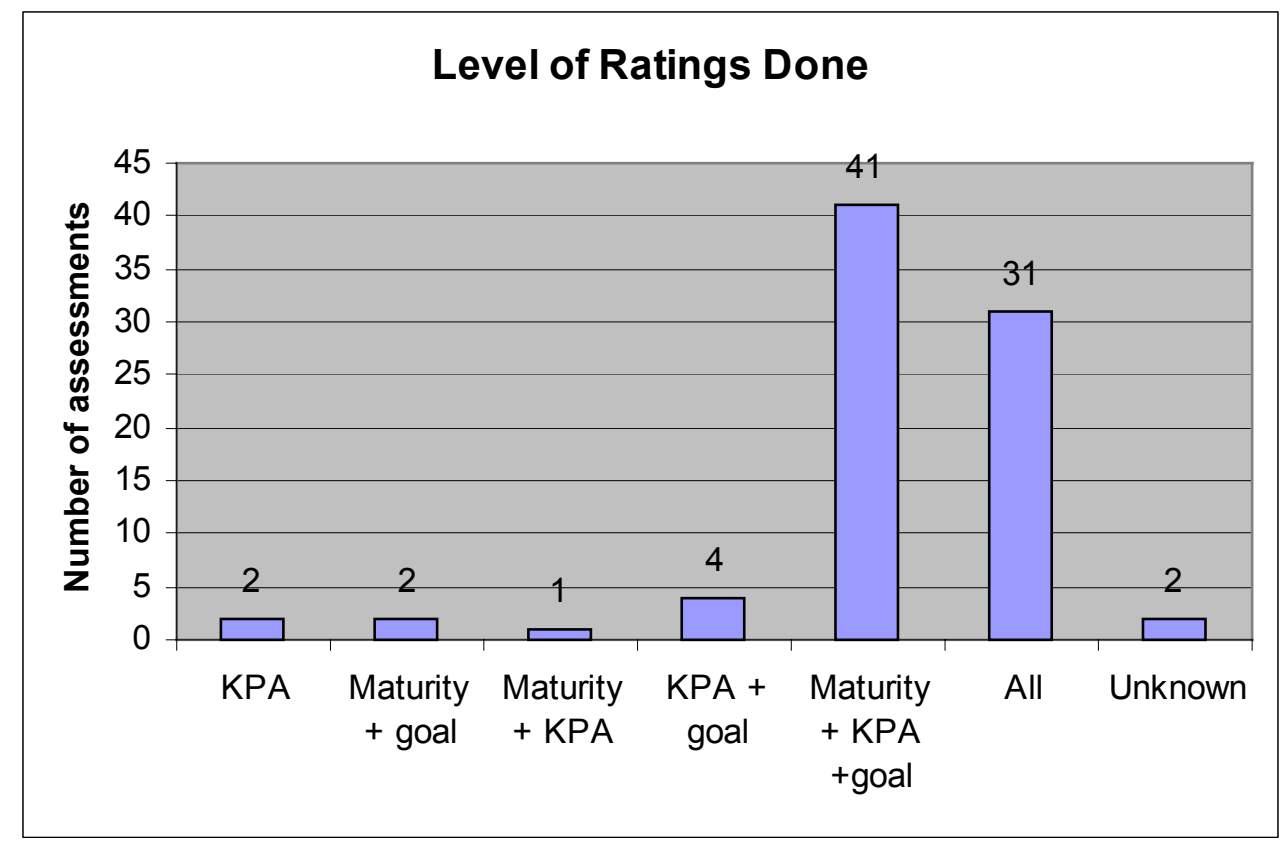

Figure 23: Level of Ratings Done

\subsection{Decision Making Strategy}

\section{CBA IPI Requirement}

Consensus is the decision-making strategy of an assessment team.
How This Assessment Was Implemented

Decisions were made by consensus of the assessment team. yes no. If not, please explain.

The data from the 83 assessments indicate that all the teams used consensus as their decisionmaking strategy. 


\section{Reporting Results}

\subsection{Sponsor Participation}

\begin{tabular}{|l|l|}
\hline CBA IPI Requirement & How This Assessment Was Implemented \\
\hline $\begin{array}{l}\text { A final findings briefing must be given } \\
\text { to the sponsor. }\end{array}$ & $\begin{array}{l}\text { The sponsor attended the: } \\
\text { Opening Meeting }\end{array}$ \\
& Final Findings Briefing \\
& Executive Session \\
\hline
\end{tabular}

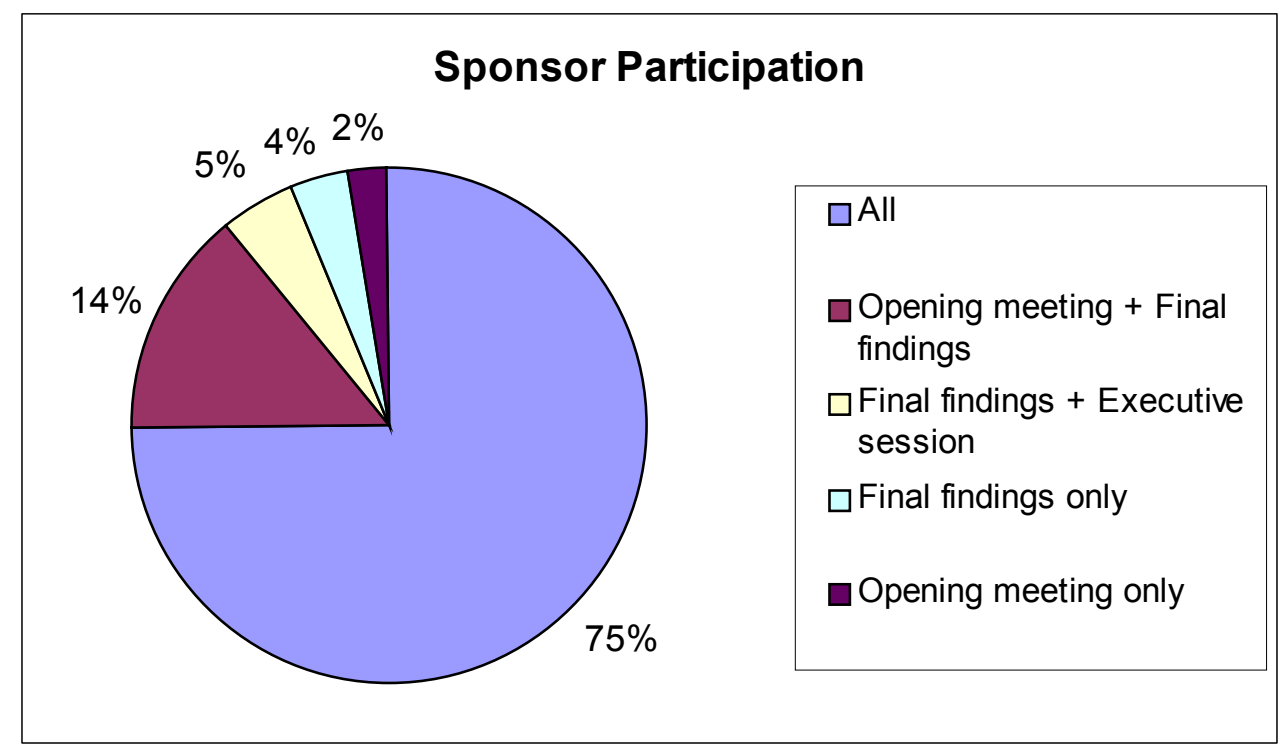

Figure 24: Sponsor Participation

In $75 \%$ of the assessed organizations, the sponsor attended all three of the meetings. Only $2 \%$ ( 2 out of 83 ) of the assessments had sponsors who only attended the Opening Meeting and did not meet the CBA IPI requirement. 


\subsection{Reports Submitted}

\begin{tabular}{|l|l|}
\hline CBA IPI Requirement & How This Assessment Was Implemented \\
\hline $\begin{array}{l}\text { The final findings briefing along } \\
\text { with the KPA profile must be sub- } \\
\text { mitted to the SEI within 30 days of } \\
\text { the conclusion of the assessment. }\end{array}$ & $\begin{array}{c}\text { The following are being submitted to the SEI: } \\
\text { PAIS report with Organization and Project }\end{array}$ \\
& $\begin{array}{l}\text { Questionnaires } \\
\text { Final findings briefing with KPA profile } \\
\text { Required feedback forms (incl. this checklist) } \\
\text { Assessment plan }\end{array}$ \\
\end{tabular}

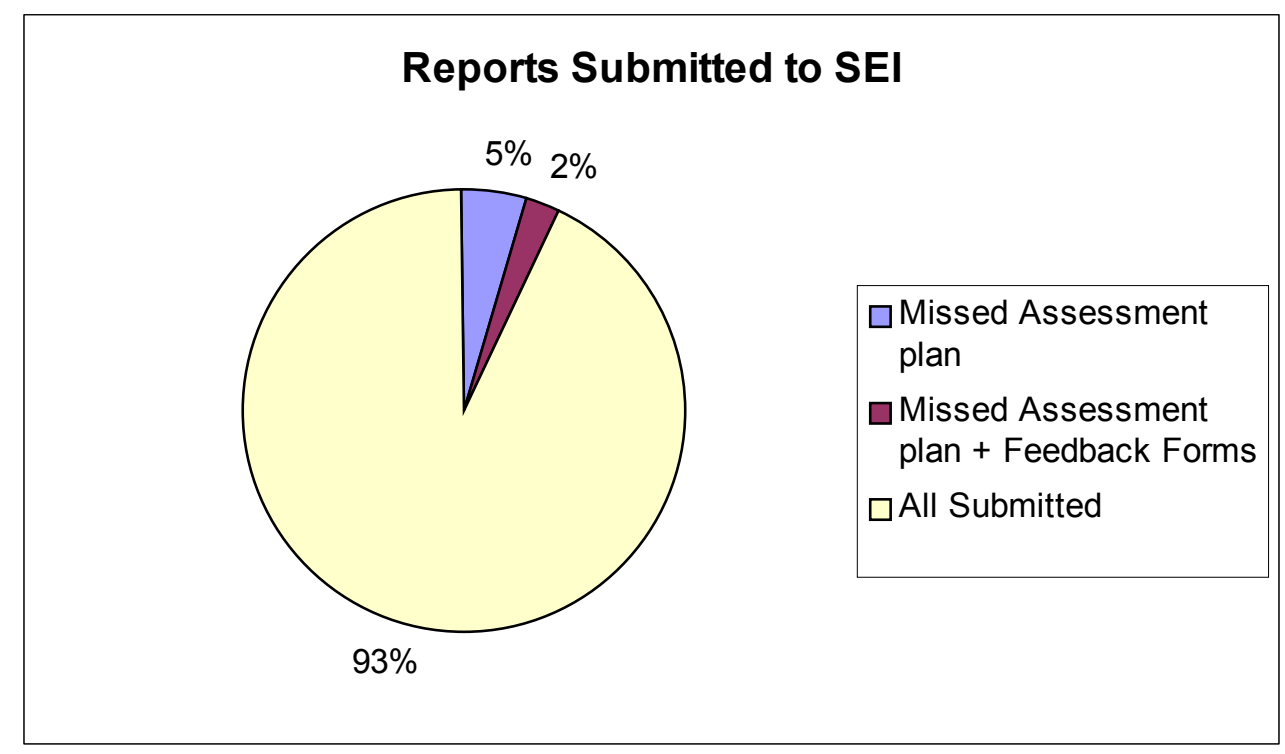

Figure 25: Reports Submitted to the SEI

The CBA IPI requirement states that the final findings briefing along with the KPA profile must be submitted to the SEI. The responses from the 83 assessments indicated that this was done for all of the 83 the assessments. 77 out of the 83 assessments submitted all of the other documents as well, while the rest either did not submit the assessment plan or failed to submit both the assessment plan and the feedback forms. 


\section{Additional Questions}

\subsection{Length of Assessments}

In the beginning of the Lead Assessor Requirements Checklist, the beginning and end dates of the CBA IPI are recorded. Based on these dates, the number of days for each assessment can be computed, ignoring any weekends or public holidays. The following histogram shows the distribution of the number of assessment days for the 83 assessments.

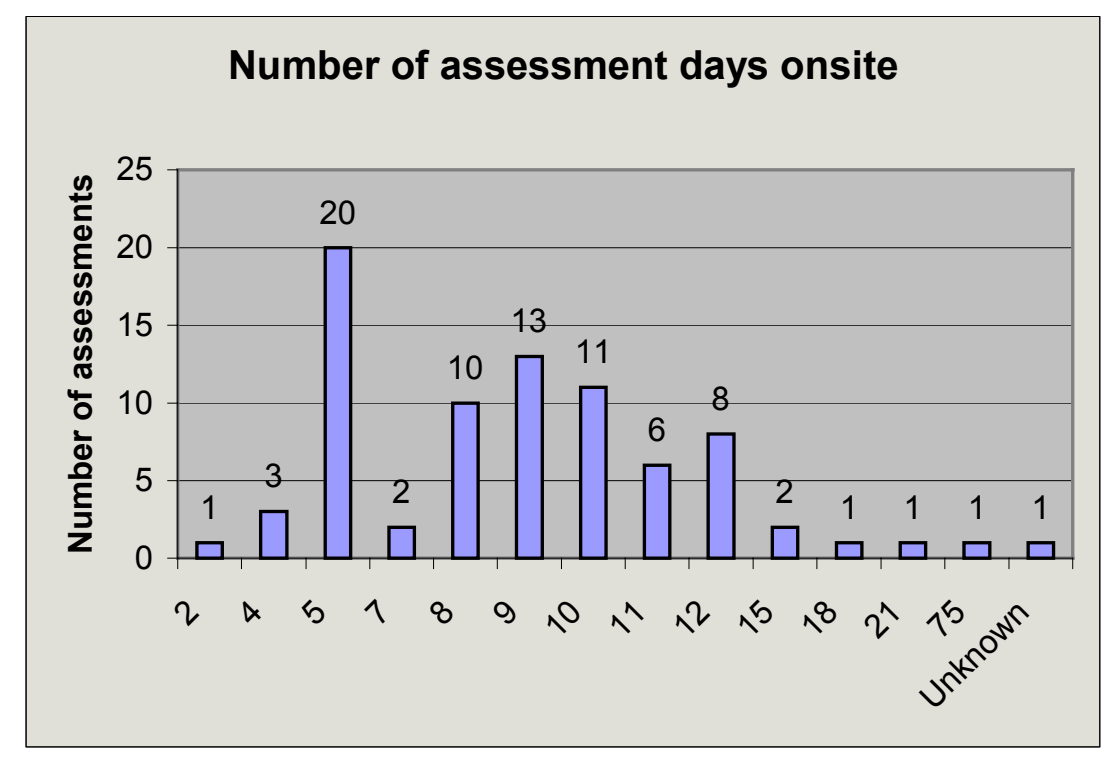

Figure 26: Number of Assessment Days

The figure above indicates that the most frequent assessment length is 5 days (20 assessments, approximately $24 \%$ ). This is followed by assessments that last from 8 to 10 days. The average number of days for an assessment is nine days (based on a total of 82 assessments, excluding the one that did not provide the assessment dates).

\subsection{Team Hours}

\section{CBA IPI Requirement}

How many team-hours (total number of hours the team worked together) were spent in pre-onsite activities - e.g., team training, document review, scripting questions?

How many team-hours were spent in on-site activities e.g., interviews, data consolidation, 
findings preparation and presentation?

How many team-hours were spent in data

consolidation activities?

The responses for these questions in the Lead Assessor Requirements Checklist had a very wide variance.

These figures were adjusted for consistency. There were different interpretations of the term "team-hours." Some Lead Assessors interpreted "team-hours" to mean total person-hours, and multiplied the number of team members by the time spent by each team member. The intention of these questions is that "team-hours" refer to the total amount of time that the team spends together on team activities in that particular phase (pre-onsite, on-site or reporting). The questions will be clarified to eliminate confusion in the future.

The first two questions are intended to identify the distribution of team-hours spent in preonsite versus on-site activities of a CBA IPI assessment. The third question, however, refers specifically to consolidation activities only, which is a part of the on-site activities.

\begin{tabular}{|l|l|l|l|}
\hline & \multicolumn{1}{|c|}{$\begin{array}{c}\text { Minimum } \\
\text { team-hours }\end{array}$} & $\begin{array}{l}\text { Median team- } \\
\text { hours }\end{array}$ & $\begin{array}{c}\text { Maximum } \\
\text { team-hours }\end{array}$ \\
\hline Pre-onsite activities & 5 & 35 & 70 \\
\hline On-site activities & 32 & 62 & 117 \\
\hline $\begin{array}{l}\text { Consolidation activities (in- } \\
\text { cluded in on-site activities) }\end{array}$ & 3 & 19 & 47 \\
\hline Total Team Hours & 48 & 97 & 198 \\
\hline
\end{tabular}

\subsubsection{Pre-onsite and On-Site Time Distribution}

Approximately $50 \%$ of the teams spend less than 35 hours on pre-onsite activities and less than 62 hours on on-site activities, shown as the medians on the table above. The proportion of pre-onsite activities to on-site activities is indicated from data on 80 assessments, discarding the 3 assessments that did not have responses to all 3 questions above. On the average, teams spend $34 \%$ of the assessment time on pre-onsite activities and $66 \%$ on on-site activities. 


\section{Average distribution of total team hours}

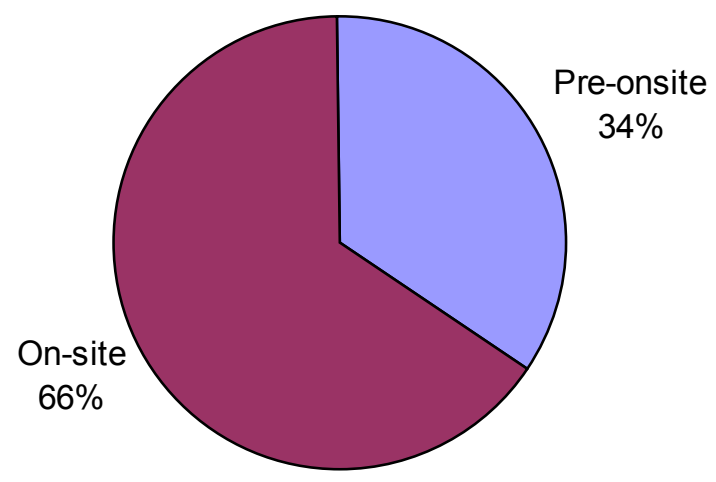

Figure 27: Average Distribution of Total Team Hours

\subsubsection{Team Hours Spent on Consolidation Activities}

It has been noted that consolidation activities are a major time requirement during the on-site phase. Therefore, a question is included in the Lead Assessor Requirements Checklist, which explicitly asks about time spent on consolidation activities. This information makes it possible to study the proportion of time required for the on-site activities relative to consolidation.

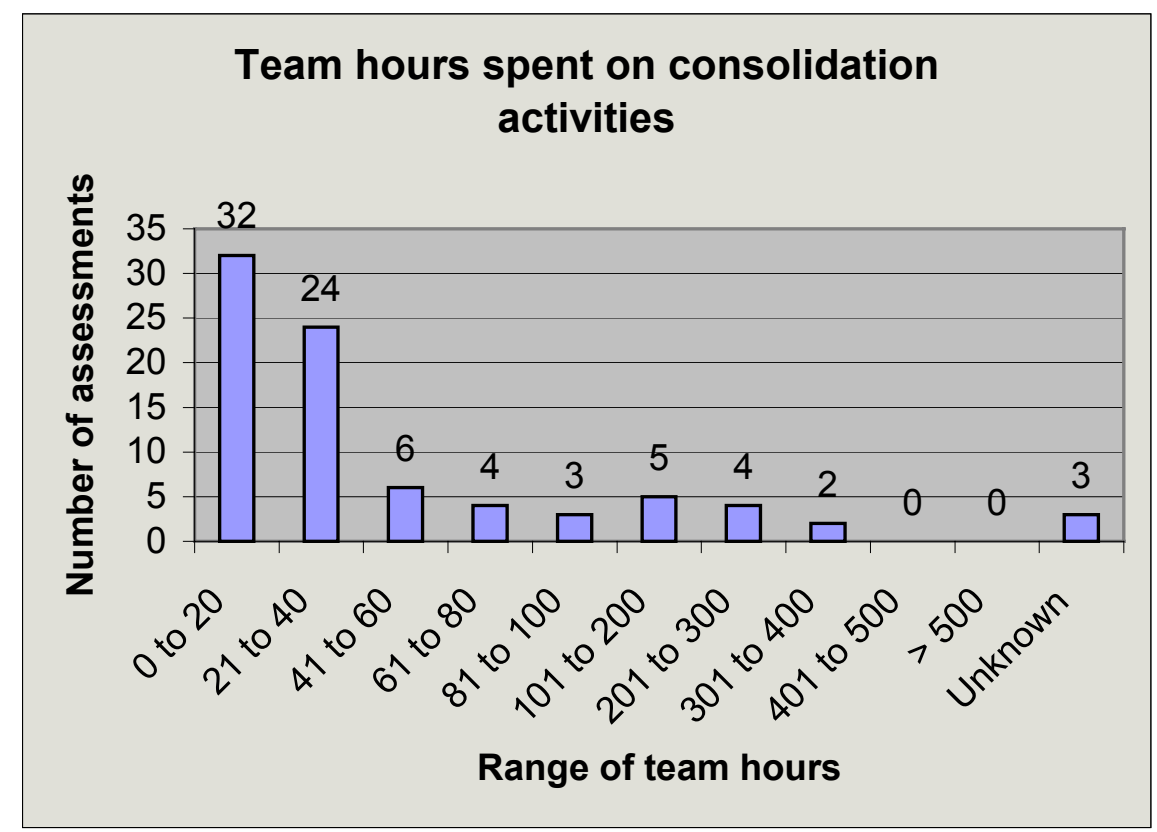

Figure 28: Team Hours Spent on Consolidation Activities

Figure 28 shows the range of team hours spent by various teams. 32 teams spent less than 20 hours on consolidation activities, while 24 teams spent between 21 to 40 hours. 
It is also interesting to consider the team hours spent on consolidation activities with respect to the total team hours. This percentage may be calculated, assuming that: there is no overlap in the values provided for the pre-onsite and on-site activities; and the team hours provided for the consolidation activities is a subset of that for the on-site activities. The sum of the values provided for the pre-onsite activities and on-site activities is used as the total team hours for each assessment. The results of this computation are shown below. 42\% (35 out of 83) of the assessments spent between 11 to $20 \%$ of their total team hours on consolidation activities. The average proportion is $20 \%$.

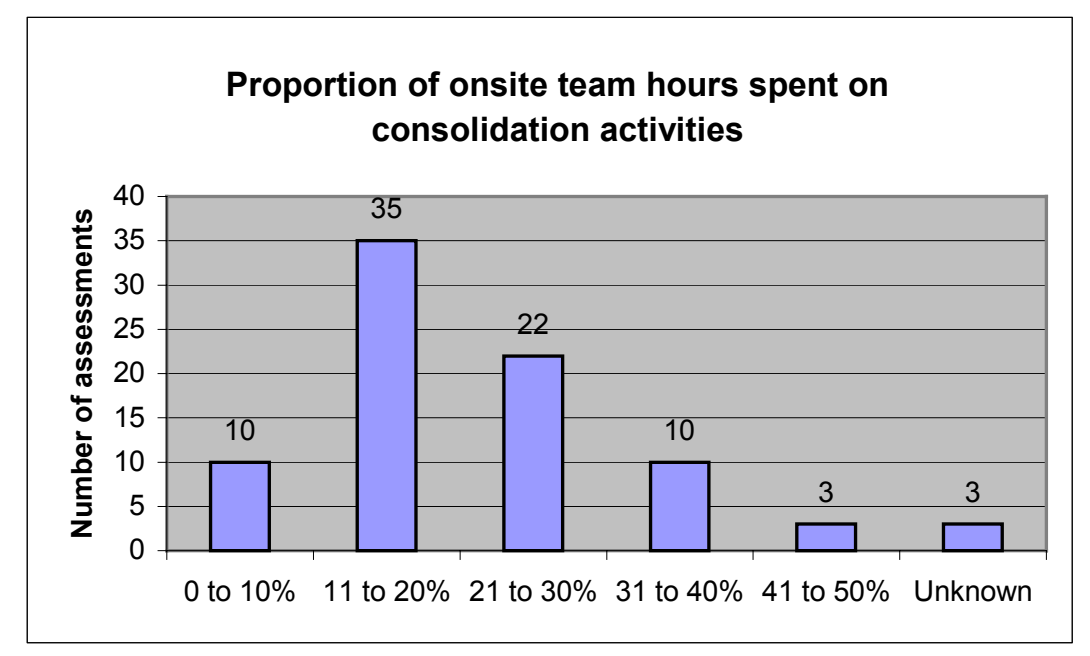

Figure 29: Proportion of On-Site Team Hours Spent on Consolidation Activities

\subsubsection{Team Hours Required to Perform CBA IPI Activities}

Figure 30 below shows the time periods indicated to perform the pre-onsite and the onsite activities, as well as time spent in consolidation activities. The chart shows the largest observed value, the smallest observed value, the median values, and the $25^{\text {th }}$ and $75^{\text {th }}$ percentiles for each of the three sets of measures. 


\section{Time to Perform CBA IPI Activities}
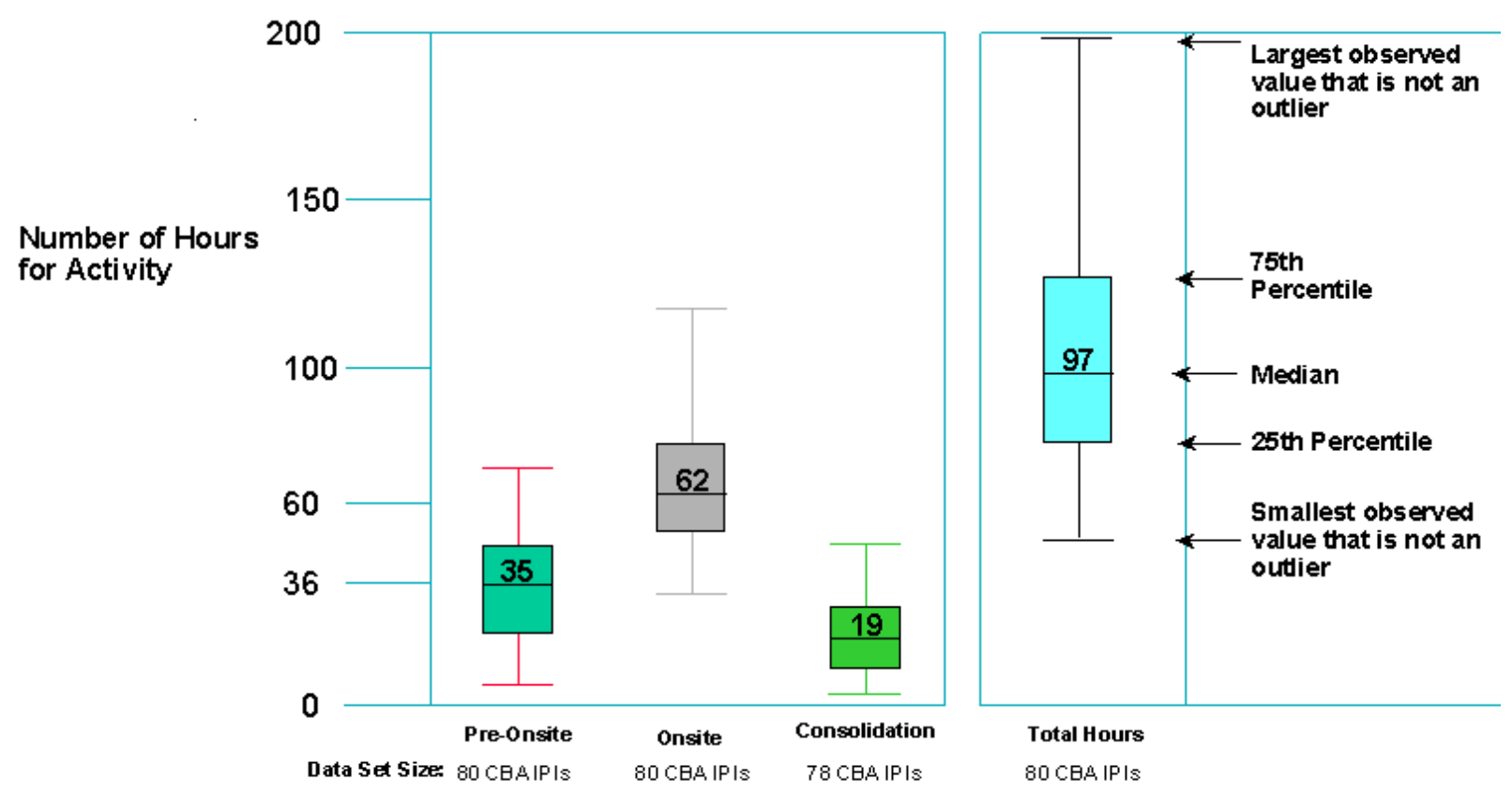

Time Period for Assessment

Figure 30: Time to Perform CBA IPI Activities 


\section{Conclusion}

\subsection{CBA IPI Requirements}

Overall, the data from the Lead Assessor Requirements Checklists submitted for 83 assessments indicate that there are no significant problems in meeting the CBA IPI requirements.

\subsection{Key Findings}

The results of analyzing the data submitted through the Lead Assessor Requirements Checklist have produced some useful information that may provide good references for future assessments. The following table summarizes some of the key findings in this document that may be useful references for Lead Assessors:

\begin{tabular}{|c|c|}
\hline Item & Findings \\
\hline \multicolumn{2}{|c|}{ Planning the Assessment } \\
\hline Team size & $\begin{array}{l}\text { Range: } 4 \text { to } 13 \text { team members } \\
\text { Average: } 7 \text { team members }\end{array}$ \\
\hline Business goals & $\begin{array}{l}\text { Top three: } \\
\text { 1. "Faster, better, cheaper" } \\
\text { 2. Attain Level } 2 \text { Maturity } \\
\text { 3. Identify improvement areas }\end{array}$ \\
\hline Organization size & Range: 5 to 934 people involved in software development \\
\hline CMM training & $31 \%$ SEI and $64 \%$ non-SEI \\
\hline CBA IPI training & Most frequent delivery time: $16-20$ hours \\
\hline Supplementary materials & $\begin{array}{l}\text { Top } 3 \text { areas supplemented: } \\
\text { 1. Automation tools } \\
\text { 2. Exercises } \\
\text { 3. Planning \& team building }\end{array}$ \\
\hline \multicolumn{2}{|c|}{ Conducting the Assessment } \\
\hline Maturity questionnaires & $\begin{array}{l}\text { Range: } 0 \text { to } 47 \text { questionnaires } \\
\text { Most frequent number administered: } 0 \text { to } 5 \text { questionnaires }\end{array}$ \\
\hline Interviews & Most frequent total number of interviews: 21 to 30 \\
\hline Documents reviewed & Most frequent number of documents reviewed: 10 to 100 \\
\hline Observations & Range: 7 to 3000 observations \\
\hline Draft findings & $\begin{array}{l}\text { Range of draft findings presented: } 1 \text { to } 236 \\
\text { Most frequent number of presentations: } 2\end{array}$ \\
\hline \multicolumn{2}{|l|}{ Additional Questions } \\
\hline Length of assessments & $\begin{array}{l}\text { Most frequent length: } 5 \text { days } \\
\text { Average: } 9 \text { days }\end{array}$ \\
\hline Team hours & $\begin{array}{l}\text { Median number of team-hours for pre-onsite activities: } 35 \\
\text { Median number of team-hours for on-site activities: } 62\end{array}$ \\
\hline
\end{tabular}




\begin{tabular}{|l|l|}
\hline Item & Findings \\
\hline & $\begin{array}{l}\text { Median number of team-hours for consolidation: 19 } \\
\text { Median number of total team-hours: 97 }\end{array}$ \\
\hline
\end{tabular}

\subsection{Lead Assessor Requirements Checklist}

Analysis of the data included in this report has provided considerable insight into the measures related to conducting a CBA IPI assessment. It has also provided guidance that will help towards improving the checklist when it is incorporated as one of several feedback forms to reside on the Lead Assessor Web Center.

Many thanks to each of the Lead Assessors who provided this data. We hope that the checklist was a useful planning tool for you and not just added administrative overhead. Your contributions of data provide a tool for yourself and other Lead Assessors in doing a better job of planning a CBA IPI for future assessment opportunities. 


\begin{tabular}{|c|c|c|c|c|}
\hline \multicolumn{3}{|c|}{ REPORT DOCUMENTATION PAGE } & & $\begin{array}{l}\text { Form Approved } \\
\text { OMB No. 0704-0188 }\end{array}$ \\
\hline \multicolumn{5}{|c|}{$\begin{array}{l}\text { Public reporting burden for this collection of information is estimated to average } 1 \text { hour per response, including the time for reviewing instructions, searching } \\
\text { existing data sources, gathering and maintaining the data needed, and completing and reviewing the collection of information. Send comments regarding this } \\
\text { burden estimate or any other aspect of this collection of information, including suggestions for reducing this burden, to Washington Headquarters Services, } \\
\text { Directorate for information Operations and Reports, } 1215 \text { Jefferson Davis Highway, Suite 1204, Arlington, VA 22202-4302, and to the Office of Management } \\
\text { and Budget, Paperwork Reduction Project (0704-0188), Washington, DC 20503. }\end{array}$} \\
\hline 1. & $\begin{array}{l}\text { AGENCY USE ONLY } \\
\text { (LEAVE BLANK) }\end{array}$ & 2. REPORT DATE & & $\begin{array}{l}\text { REPORT TYPE AND DATES COVERED } \\
\text { Final }\end{array}$ \\
\hline 4. & \multicolumn{2}{|c|}{$\begin{array}{l}\text { TITLE AND SUBTITLE } \\
\text { Analysis of Lead Assessor Feedback for CBA IPI } \\
\text { Assessments Conducted July 1998-October } 1999 .\end{array}$} & & $\begin{array}{l}\text { FUNDING NUMBERS } \\
\text { C - F19628-95-C-0003 }\end{array}$ \\
\hline & \multicolumn{2}{|c|}{$\begin{array}{l}\text { AUTHOR(s) } \\
\text { Donna Dunaway, Ph.D., Mui Leng Seow, Michele } \\
\text { Baker }\end{array}$} & & \\
\hline & \multicolumn{2}{|c|}{$\begin{array}{l}\text { PERFORMING ORGANIZATION NAME(S) AND ADDRESS(ES) } \\
\text { Software Engineering Institute } \\
\text { Carnegie Mellon University } \\
\text { Pittsburgh, PA } 15213\end{array}$} & & $\begin{array}{l}\text { PERFORMING ORGANIZATION } \\
\text { REPORT NUMBER } \\
\text { CMU/SEI-2000-TR-005 }\end{array}$ \\
\hline & \multicolumn{2}{|c|}{$\begin{array}{l}\text { SPONSORING/MONITORING AGENCY NAME(S) AND ADDRESS(ES) } \\
\text { HQ ESC/XPK } \\
5 \text { Eglin Street } \\
\text { Hanscom AFB, MA 01731-2116 }\end{array}$} & 10. & $\begin{array}{l}\text { SPONSORING/MONITORING } \\
\text { AGENCY REPORT NUMBER } \\
\text { ESC-TR-2000-005 }\end{array}$ \\
\hline
\end{tabular}

11. SUPPLEMENTARY NOTES

12.A DISTRIBUTION/AVAILABILITY STATEMENT

12.B DISTRIBUTION CODE

Unclassified/Unlimited, DTIC, NTIS

13. abstract (maximum 200 words)

In the Appraiser Program of the Software Engineering Institute (SEI), authorized Lead Assessors lead Capability Maturity Model-Based Appraisals for Internal Process Improvement (CBA IPI). At the conclusion of each assessment, they are required to submit certain artifacts to the SEI. Data from assessments is recorded to provide the community with information on the state of the software community's process maturity, as related to the Capability Maturity Model (CMM) for Software Version 1.1. These data can be viewed on the SEI Web site: <URL http:// www.sei.cmu.edu/sema/profile.html>.

Additional feedback data are required of a Lead Assessor in order to monitor the consistency of use of the assessment method for quality control purposes. Data are collected from Lead Assessors, assessment team members, and sponsors of the assessments. The results reported in this document reflect information sent to the SEI by Lead Assessors through a Lead Assessor's Requirements Checklist. The checklist aids the Lead Assessors in keeping track of their implementation of each of the method's requirements. The checklist also provides information back to the community regarding metrics being reported by Lead Assessors; this helps in more effective planning for future assessments. In addition, the checklist acts as a quality control mechanism to monitor the consistency of use of each of the method's activities.

\begin{tabular}{|c|c|c|c|c|c|c|c|}
\hline \multicolumn{5}{|c|}{$\begin{array}{l}\text { 14. SUBJECT TERMS } \\
\text { Lead Assessor Feedback, CBA IPI Assessments }\end{array}$} & \multicolumn{3}{|c|}{$\begin{array}{ll}\text { 15. NUMBER OF PAGES } \\
38\end{array}$} \\
\hline & & & & & & & \\
\hline \multirow[t]{2}{*}{7.} & $\begin{array}{l}\text { SECURITY CLASSIFICATION } \\
\text { OF REPORT }\end{array}$ & 18. & $\begin{array}{l}\text { SECURITY } \\
\text { CLASSIFICATION OF } \\
\text { THIS PAGE }\end{array}$ & 19. & $\begin{array}{l}\text { SECURITY } \\
\text { CLASSIFICATION } \\
\text { OF ABSTRACT }\end{array}$ & 20. & LIMITATION OF ABSTRACT \\
\hline & UNCLASSIFIED & & UNCLASSIFIED & & UNCLASSIFIED & & UL \\
\hline \multicolumn{5}{|c|}{ NSN 7540-01-280-5500 } & \multicolumn{3}{|c|}{$\begin{array}{l}\text { Standard Form } 298 \text { (Rev. 2-89) } \\
\text { Prescribed by ANSI Std. Z39-18 } \\
298-102\end{array}$} \\
\hline
\end{tabular}


